\title{
How Satiating Are the 'Satiety' Peptides: A Problem of Pharmacology versus Physiology in the Development of Novel Foods for Regulation of Food Intake
}

\author{
Jia Jiet Lim ${ }^{1,2(1)}$ and Sally D. Poppitt $2,3, *$ (D) \\ 1 Human Nutrition Unit, School of Biological Sciences, University of Auckland, Auckland 1024, New Zealand \\ 2 Riddet Institute, Palmerston North 4442, New Zealand \\ 3 Human Nutrition Unit, Department of Medicine, School of Biological Sciences, University of Auckland, \\ Auckland 1024, New Zealand \\ * Correspondence: s.poppitt@auckland.ac.nz; Tel.: +64-9-630-5160
}

Received: 17 May 2019; Accepted: 28 June 2019; Published: 4 July 2019

\begin{abstract}
Developing novel foods to suppress energy intake and promote negative energy balance and weight loss has been a long-term but commonly unsuccessful challenge. Targeting regulation of appetite is of interest to public health researchers and industry in the quest to develop 'functional' foods, but poor understanding of the underpinning mechanisms regulating food intake has hampered progress. The gastrointestinal (GI) or 'satiety' peptides including cholecystokinin (CCK), glucagon-like peptide 1 (GLP-1) and peptide YY (PYY) secreted following a meal, have long been purported as predictive biomarkers of appetite response, including food intake. Whilst peptide infusion drives a clear change in hunger/fullness and eating behaviour, inducing GI-peptide secretion through diet may not, possibly due to modest effects of single meals on peptide levels. We conducted a review of 70 dietary preload (DIET) and peptide infusion (INFUSION) studies in lean healthy adults that reported outcomes of CCK, GLP-1 and PYY. DIET studies were acute preload interventions. INFUSION studies showed that minimum increase required to suppress ad libitum energy intake for CCK, GLP-1 and PYY was 3.6-, 4.0- and 3.1-fold, respectively, achieved through DIET in only 29\%, 0\% and $8 \%$ of interventions. Whether circulating 'thresholds' of peptide concentration likely required for behavioural change can be achieved through diet is questionable. As yet, no individual or group of peptides can be measured in blood to reliably predict feelings of hunger and food intake. Developing foods that successfully target enhanced secretion of GI-origin 'satiety' peptides for weight loss remains a significant challenge.
\end{abstract}

Keywords: appetite; satiety; cholecystokinin; glucagon-like peptide-1; peptide YY; dietary studies; infusion studies

\section{Introduction}

Developing novel foods that can enhance satiety and reduce overconsumption in overweight individuals is an important target in the quest for weight loss. It has long been proposed that the satiating effect of a food can be optimised by modifying components including the macronutrient composition and physicochemical structural properties [1], and clearly novel food products where efficacy can be demonstrated are likely to be of both public health and commercial value in the current environment. However, a better understanding of the causal mechanisms that regulate food intake is required to progress this area. Despite a significant and growing literature, fundamental questions regarding the physiological regulation of food intake remain unanswered. 
The focus of this review is the gastrointestinal (GI)-derived, or commonly termed 'satiety', peptides, which include cholecystokinin (CCK), glucagon-like peptide-1 (GLP-1) and peptide YY (PYY). They are secreted from both the proximal and distal intestine in response to the arrival of nutrients into the intestinal tract [2-7]. Certainly, these peptides play a role in digestion and absorption of foods within the GI tract [8-10]. These peptides have long been purported to be predictive biomarkers which can provide a snapshot of subjective feelings of appetite and future food intake. Although the increase in circulating GI peptide concentrations is observed to occur concurrent with suppression of appetite following ingestion of a meal, the increased circulating GI peptides in turn drive appetite-related responses has yet to be satisfactory demonstrated in dietary intervention trials (Figure 1). Another major challenge faced by dietary preload studies looking to support this hypothesis is the need to disentangle the direct effect of GI peptides on hunger suppression from other potential anorectic stimulants associated with food intake.

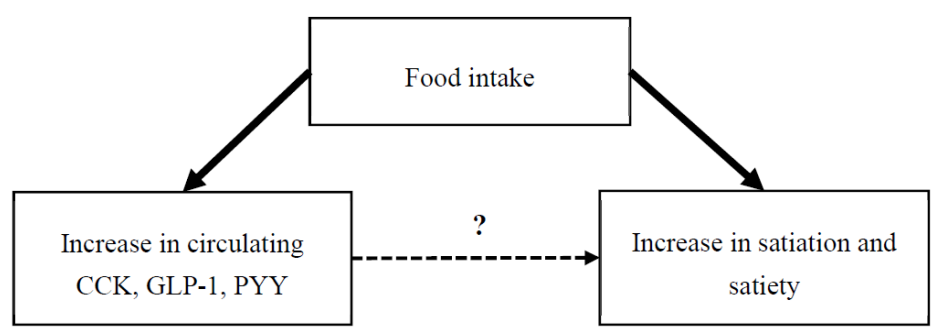

Figure 1. Food intake induces an increase in circulating gastrointestinal peptides CCK, GLP-1 and PYY, as well as parallel increase in satiation and satiety. However, whether these 'satiety' peptides in turn elicit a direct physiological effect on aspects of eating behaviour is less well-understood.

Robust evidence from dietary intervention trials is required to substantiate any appetite-related claims to be made on food products. A standardised international methodology for assessing acute satiety effects of food ingredients, products and meals was described by the International Life Sciences Institute (ILSI) working group led by Blundell, et al. [11] as the dietary preload study. This study design requires consumption of a fixed meal as dietary preload, with postprandial response assessed through measurement of subjective feeling of appetite, such as hunger or fullness, using visual analogue scales (VAS), followed by measurement of ad libitum food intake at an outcome meal at a fixed time interval post-preload. The European Food Safety Authority (EFSA) recognises VAS-assessed change in appetite ratings and energy intake as an appropriate outcome measure of mechanisms in support of weight loss (EFSA 2012). Therefore, we were interested to review the current dietary literature investigating trials that have adhered to this EFSA standard to determine whether optimising a food product to target the 'satiety' peptides is a reasonable strategy for development of novel foods.

In contrast to the dietary studies, intravenous infusion of GI peptides in the fasted state leads to a significant and rapid increase in circulating GI peptide concentration, and there is a clear suppression of food intake. These studies, presented in detail later in this review and commonly known as peptide infusion studies, have collectively shown that GI peptide receptors can be potential therapeutic targets for obesity, with peptide signalling pathways also being elucidated [12,13]. Anti-obesity drugs targeting peptide receptors show some efficacy in clinical studies [14]. GLP-1 receptor agonists are well known for treatment of type 2 diabetes [15] and also show some promise for weight control $[16,17]$. Nevertheless, these are pharmacological mechanisms. Essentially, appetite suppression is generally more pronounced in peptide infusion studies than in dietary preload studies, and most importantly, circulating GI peptides are characteristically higher following infusion than following a meal [18]. The question on physiological mechanism, whether postprandial increase in GI peptides causes the suppression of food intake or not, is not satisfactorily answered by peptide infusion studies.

Mars, Stafleu and de Graaf [18] previously reviewed the utility of measuring circulating GI peptides in appetite studies and was unable to conclude that circulating GI peptides are useful indicators of appetite. Their results also challenged the relevance of developing novel food products 
targeting GI peptides as a mechanism by which to suppress daily energy intake. Our current review builds on this earlier analysis [18] and aims to further explore the relationship between GI peptides and appetite outcomes, in addition to discussing the relevance of targeting mechanisms of GI peptides during the development of novel food products. The primary objective of this review was to assess whether there were differences in baseline peptide concentration, $\mathrm{C}_{\max }$, and fold change from baseline between dietary preload (DIET) studies and peptide infusion (INFUSION) studies. The secondary objective was to explore whether there was an association between peptide concentration and appetite outcomes in both groups.

\section{Materials and Methods}

An online literature search was conducted by J.J.L. for relevant articles published on PubMed. Original studies were identified by using the following keywords: "energy intake" or "appetite" or "satiety" or "eating", in combination with "cholecystokinin" or "glucagon-like peptide-1" or "peptide YY" or their abbreviations (CCK, GLP-1 and PYY respectively). Relevant articles were initially selected based on the title and abstract. The articles selected were required to be original studies conducted as either dietary preload (DIET) studies or peptide infusion (INFUSION) studies, written in the English language. Initial searches were carried out for articles published between year 2003 and 2017. However, due to the small number of published of peptide infusion studies, searches for peptide infusion studies were extended to 1993. The references of selected articles were also examined to identify any further relevant articles.

Studies were selected based on the following criteria: (i) Dietary preload study conducted using a standardised preload design, as described by Blundell et al. [11] where a fixed preload was consumed, and an outcome meal provided after a fixed time interval from which the participant could eat freely (ad libitum); or peptide infusion study conducted using intravenous peptide infusion as treatments and saline infusion as control, (ii) human clinical studies, (iii) lean cohort with mean BMI $<25.0 \mathrm{~kg} / \mathrm{m}^{2}$, (iv) no clinically diagnosed disorders. The studies were included if baseline and peak $\left(\mathrm{C}_{\max }\right)$ concentration of CCK, GLP-1 or/and PYY were reported in text or could otherwise be extracted from Figures showing change of concentration across time. Some missing data were obtained from the authors. Studies were excluded if interventions were targeted towards trained athletes, or centred on a specific age range, such as children, young adults or elderly, as these groups did not represent a typical lean and healthy adults. Furthermore, studies which allowed participants to request the outcome meal spontaneously were excluded due to the difficulty in characterising mean $\mathrm{C}_{\max }$ of GI peptides prior to consumption of the outcome meal. Studies were also excluded if they involved additional intervention, such as exercise. Additionally, any preload meals containing less than $1 \mathrm{MJ}$ were excluded, as they represented a small meal.

Data collected include the duration between preload meal and outcome meal, energy and macronutrient composition of preload meal, baseline peptide concentrations, peak peptide concentrations, and ad libitum energy intake at the outcome meal. Where peptide concentrations were only available in the form of graphs, this was manually measured using the PDF-measurement tool (Adobe Acrobat Pro DC, Burlington, NJ, USA). This tool enables the measurement of the distance between two points on the graph to the lower detection limit of $0.01 \mathrm{~cm}$. Fold change in relative to baseline was calculated by dividing the $\mathrm{C}_{\max }$ by the baseline concentration. Preload meal was grouped into either solid (e.g., sandwiches and composite meal) or non-solid (e.g., liquid drinks, soup, pudding and custard). Data were analysed using IBM Statistical Package for the Social Sciences (SPSS) software (version 25; IBM Corp., Armonk, NY, USA). Weighted means and medians were calculated for each peptide (CCK, GLP-1 and PYY), and grouped into dietary preload studies (DIET) or peptide infusion studies (INFUSION). Weight was applied to each intervention based on its sample size (n); therefore, a greater emphasis was given to an intervention with greater sample size. Statistical outliers were not removed from the analysis unless otherwise specified. A dot plot overlaid on a box plot was presented to demonstrate the data distribution; each dot was representative of the mean of an intervention. Data 
were reported as 'mean (95\% Confidence Interval)' unless otherwise specified. $N$ represents the total sample size while $K$ represents the number of interventions.

\section{Results}

\subsection{Search Results}

Based on the search methods described, 52 DIET articles were retrieved in full text. Of 52 articles, 9 articles were excluded due to insufficient data. Then, two articles were further excluded due to duplicate data [19] and unreliable data [20]. As a result, a total of 41 DIET articles were included in the analysis. A total of 18 INFUSION articles were included in the analysis (Figure 2).

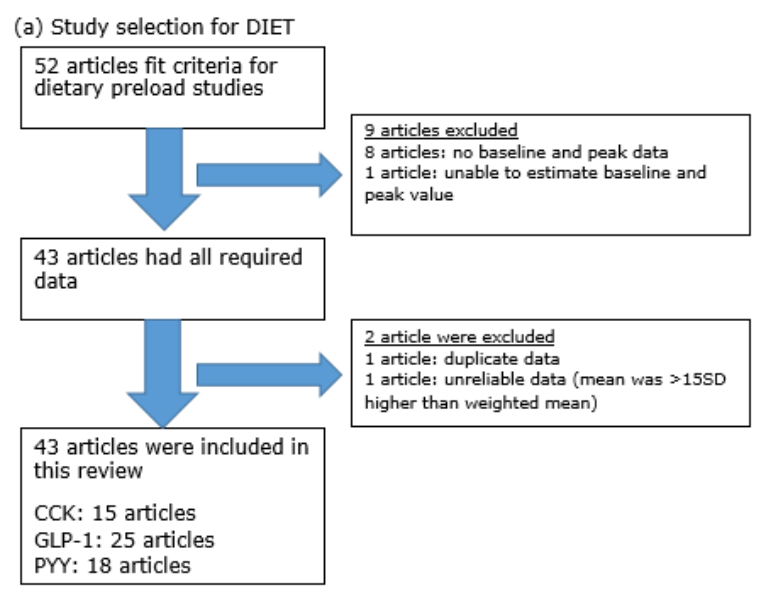

(b) Study selection for INFUSION

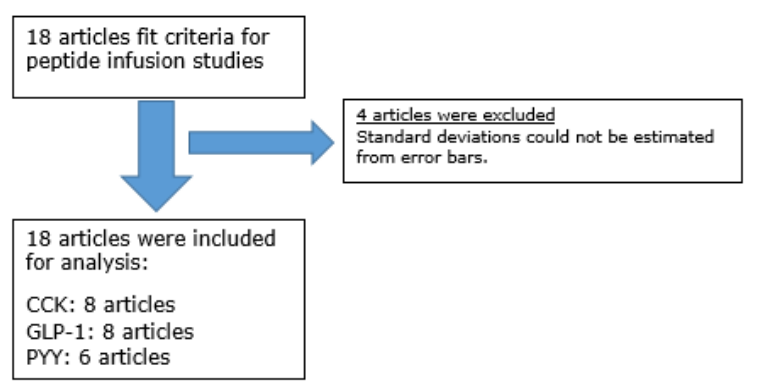

Figure 2. Flow diagram of article selection for (a) DIET and (b) INFUSION studies. Some articles reported $>1$ GI-peptide.

\subsection{Study Characteristics}

DIET comprised of 108 dietary interventions published in 41 articles (Table 1). All studies were randomised cross-over trials ( $\geq 2$ interventions in a single article). Fifty-seven interventions (53\%) had mixed gender, whereas 34 interventions ( $31 \%$ ) enrolled male participants only and 17 interventions $(16 \%)$ enrolled female participants only. The median sample size of the intervention was 17 (range: 4-40). The median duration of DIET was $180 \mathrm{~min}$ (range: $30-480 \mathrm{~min}$ ). The preload meals varied from study to study, from solid to non-solid format. The median energy supplied by the preload meal was 1.8 MJ (range: 1-12.5 MJ). The energy content of preload meals supplied by 4 interventions [21,22] were adjusted based on the participants energy requirement; whereas in other studies, preload meals supplied fixed energy to all participants within an intervention. All interventions required the preload meal to be consumed in its entirety. Each dietary intervention assessed at least one GI peptide, whilst several interventions assessed multiple peptides. For DIET, in the 41 published articles, a total of 39 interventions assessed CCK, 66 interventions assessed GLP-1 and 50 interventions assessed PYY. 
Table 1. Dietary preload (DIET) studies in lean men and women.

\begin{tabular}{|c|c|c|c|c|c|c|c|c|c|c|c|c|c|c|}
\hline \multirow{2}{*}{ Reference } & \multirow{2}{*}{ Gender } & \multirow{2}{*}{$N$} & \multirow{2}{*}{$\begin{array}{c}\text { Study } \\
\text { Duration } \\
\text { (min) }\end{array}$} & \multirow{2}{*}{ Preload Meal } & \multirow{2}{*}{ Format } & \multirow{2}{*}{$\begin{array}{c}\text { Energy } \\
\text { (MJ) }\end{array}$} & \multirow{2}{*}{$\mathrm{CHO}(\mathrm{g})$} & \multirow{2}{*}{$\begin{array}{l}\text { Protein } \\
\text { (g) }\end{array}$} & \multirow{2}{*}{ Fat (g) } & \multicolumn{3}{|c|}{ Fold Change } & \multicolumn{2}{|c|}{ Appetite Outcomes } \\
\hline & & & & & & & & & & CCK & GLP-1 & PYY & Sensation & FI (kJ) \\
\hline \multirow{2}{*}{ Nolan, et al. [23] } & $\mathrm{M}$ & 4 & 30 & Tomato soup & NS & 1.4 & 60 & 7 & 7 & 1.8 & - & - & ND & - \\
\hline & $\mathrm{F}$ & 4 & 30 & Tomato soup & NS & 1.4 & 60 & 7 & 7 & 3.9 & - & - & ND & - \\
\hline \multirow{2}{*}{ Hall, et al. [24] } & MF & 9 & 90 & Casein liquid meal & NS & 1.7 & 24 & 48 & 11 & 2.8 & 1.7 & - & FUL ${ }^{a}$ & $3676^{\mathrm{a}}$ \\
\hline & MF & 9 & 90 & Whey liquid meal & NS & 1.7 & 20 & 40 & 9 & 3.2 & 2.0 & - & FUL ${ }^{b}$ & $4537^{b}$ \\
\hline \multirow{4}{*}{ Bakhoj, et al. [25] } & $\mathrm{M}$ & 11 & 180 & Einkorn honey salt bread & S & 1.2 & 54 & 9 & 4 & - & 1.3 & - & - & - \\
\hline & $\mathrm{M}$ & 11 & 180 & Einkorn crushed WG bread & $\mathrm{s}$ & 1.2 & 54 & 9 & 4 & - & 1.3 & - & - & - \\
\hline & $\mathrm{M}$ & 11 & 180 & Einkorn yeast bread & $\mathrm{s}$ & 1.2 & 54 & 9 & 4 & - & 1.3 & - & - & - \\
\hline & $\mathrm{M}$ & 11 & 180 & Modern yeast bread & $\mathrm{s}$ & 1.2 & 50 & 8 & 3 & - & 1.2 & - & - & - \\
\hline \multirow{4}{*}{ Frost, et al. [26] } & MF & 10 & 240 & Control pasta & $\mathrm{s}$ & 1.0 & 50 & - & - & - & 1.7 & - & ND & 4807 \\
\hline & MF & 10 & 240 & Fibre enriched pasta & $\mathrm{s}$ & 1.0 & 50 & - & - & - & 1.4 & - & ND & 5167 \\
\hline & MF & 10 & 240 & Control pasta + fat & $\mathrm{s}$ & 2.1 & 50 & - & 30 & - & 2.5 & - & ND & 4837 \\
\hline & MF & 10 & 240 & Fibre enriched pasta + fat & $\mathrm{s}$ & 2.1 & 50 & - & 30 & - & 2.4 & - & ND & 4690 \\
\hline \multirow{2}{*}{ Pasman, et al. [27] } & $\mathrm{M}$ & 26 & 240 & Simple $\mathrm{CHO}$ breakfast & $\mathrm{s}$ & 1.8 & 80 & 12 & 7 & 2.5 & - & - & STT a & - \\
\hline & M & 26 & 240 & Complex $\mathrm{CHO}$ breakfast & S & 1.7 & 72 & 12 & 7 & 2.7 & - & - & STT $\mathbf{\Delta}^{\mathrm{b} 2}$ & - \\
\hline \multirow{2}{*}{ Adam [28] } & MF & 26 & 240 & Glucose & NS & 1.3 & 75 & 0 & 0 & - & 1.8 & - & STT a & ND \\
\hline & MF & 26 & 240 & Glucose + guar gum & NS & 1.3 & 75 & 0 & 0 & - & 1.5 & - & $\operatorname{STT} \Delta^{b}$ & ND \\
\hline \multirow{2}{*}{ Sanggaard, et al. [29]) } & $\mathrm{M}$ & 8 & 480 & Whole milk & NS & 3.7 & 62 & 48 & 49 & 5.0 & 3.4 & 1.9 & ND & - \\
\hline & M & 8 & 480 & Fermented milk + lactose & NS & 4.1 & 81 & 52 & 49 & 3.7 & 3.6 & 2.3 & ND & - \\
\hline \multirow{4}{*}{ Burton-Freeman [30] } & $\mathrm{MF}$ & 25 & 45 & Low fat shake & NS & 1.1 & 52 & 10 & 1 & 2.0 & - & - & STF ${ }^{a}$ & $3014^{\mathrm{a}}$ \\
\hline & MF & 25 & 45 & Safflower oil shake & NS & 1.1 & 30 & 9 & 12 & 2.4 & - & - & $\operatorname{STF} \Delta^{b}$ & $3198^{a, b}$ \\
\hline & MF & 25 & 45 & Walnut oil shake & NS & 1.1 & 30 & 10 & 12 & 2.0 & - & - & STF $^{\text {a }}$ & $3340^{a, b}$ \\
\hline & MF & 25 & 45 & Ground walnut shake & NS & 1.1 & 30 & 9 & 12 & 2.3 & - & - & $\mathrm{STF}^{\mathrm{a}}$ & $3457^{\mathrm{b}}$ \\
\hline Adam and & MF & 30 & 120 & Breakfast & NS & 1.9 & 55 & 31 & 12 & - & 1.7 & - & ND & ND \\
\hline Westerterp-Plantenga [31] & MF & 30 & 120 & Breakfast + galactose + guar gum & NS & 2.7 & 105 & 31 & 12 & - & 3.6 & - & ND & ND \\
\hline \multirow{4}{*}{ Weickert, et al. [32] } & $\mathrm{F}$ & 14 & 300 & Control bread & $\mathrm{s}$ & 1.0 & 50 & 7 & 1 & - & 2.2 & - & - & - \\
\hline & $\mathrm{F}$ & 14 & 300 & Wheat fibre bread & $\mathrm{s}$ & 1.0 & 50 & 7 & 1 & - & 1.7 & - & - & - \\
\hline & $\mathrm{F}$ & 14 & 300 & Oat fibre bread & $\mathrm{s}$ & 1.0 & 50 & 7 & 1 & - & 1.9 & - & - & - \\
\hline & MF & 25 & 180 & High protein pasta + dessert & $\mathrm{s}$ & 4.6 & 47 & 178 & 21 & - & - & 2.0 & HGR $\boldsymbol{v}^{a}$ & - \\
\hline \multirow{2}{*}{ Batterham, et al. [33] } & MF & 25 & 180 & High $\mathrm{CHO}$ pasta + dessert & $\mathrm{s}$ & 4.6 & 176 & 48 & 21 & - & - & 1.4 & $\mathrm{HGR}^{\mathrm{b}}$ & - \\
\hline & MF & 25 & 180 & High fat pasta + dessert & $\mathrm{s}$ & 4.6 & 46 & 46 & 80 & - & - & 1.8 & HGR $\boldsymbol{r}^{a}$ & - \\
\hline
\end{tabular}


Table 1. Cont

\begin{tabular}{|c|c|c|c|c|c|c|c|c|c|c|c|c|c|c|}
\hline \multirow{2}{*}{ Reference } & \multirow{2}{*}{ Gender } & \multirow{2}{*}{$N$} & \multirow{2}{*}{$\begin{array}{c}\text { Study } \\
\text { Duration } \\
\text { (min) }\end{array}$} & \multirow{2}{*}{ Preload Meal } & \multirow{2}{*}{ Format } & \multirow{2}{*}{$\begin{array}{c}\text { Energy } \\
\text { (MJ) }\end{array}$} & \multirow{2}{*}{$\mathrm{CHO}(\mathrm{g})$} & \multirow{2}{*}{$\begin{array}{l}\text { Protein } \\
\text { (g) }\end{array}$} & \multirow{2}{*}{ Fat (g) } & \multicolumn{3}{|c|}{ Fold Change } & \multicolumn{2}{|c|}{ Appetite Outcomes } \\
\hline & & & & & & & & & & CCK & GLP-1 & PYY & Sensation & FI (kJ) \\
\hline \multirow{2}{*}{ Blom, et al. [34] } & $\mathrm{M}$ & 15 & 180 & High $\mathrm{CHO}$ plain yoghurt & NS & 1.6 & 46 & 19 & 14 & 3.9 & 1.5 & - & ND & 5136 \\
\hline & M & 15 & 180 & High protein whey isolates & NS & 1.7 & 14 & 57 & 12 & 7.9 & 2.0 & - & ND & 4697 \\
\hline \multirow{6}{*}{ le Roux, et al. [35] } & MF & 20 & 180 & Liquid meal $(500 \mathrm{~mL})$ & NS & 1.0 & 42 & 16 & 10 & - & - & 2.0 & - & - \\
\hline & MF & 20 & 180 & Liquid meal $(500 \mathrm{~mL})$ & NS & 2.2 & 52 & 18 & 27 & - & - & 2.4 & - & - \\
\hline & MF & 20 & 180 & Liquid meal $(500 \mathrm{~mL})$ & NS & 4.2 & 63 & 17 & 75 & - & - & 3.2 & - & - \\
\hline & MF & 20 & 180 & Liquid meal $(900 \mathrm{~mL})$ & NS & 4.2 & 99 & 33 & 53 & - & - & 2.9 & - & - \\
\hline & MF & 20 & 180 & Liquid meal $(900 \mathrm{~mL})$ & NS & 8.4 & 108 & 30 & 162 & - & - & 3.7 & - & - \\
\hline & MF & 20 & 180 & Liquid meal (900 mL) & NS & 12.5 & 85 & 25 & 275 & - & - & 4.2 & - & - \\
\hline \multirow{3}{*}{ Weickert, et al. [36] } & $\mathrm{F}$ & 12 & 300 & Control bread & $\mathrm{s}$ & 1.0 & 50 & 7 & 1 & - & - & 1.5 & ND & - \\
\hline & $\mathrm{F}$ & 12 & 300 & Wheat fibre bread & $\mathrm{s}$ & 1.0 & 50 & 7 & 1 & - & - & 1.1 & ND & - \\
\hline & $\mathrm{F}$ & 12 & 300 & Oat fibre bread & S & 1.0 & 50 & 7 & 1 & - & - & 1.4 & ND & - \\
\hline Doucet, et al. [37] & $\mathrm{F}$ & 25 & 180 & Standard breakfast & $\mathrm{s}$ & 2.4 & 82 & 19 & 19 & - & - & 1.7 & - & 2249 \\
\hline \multirow{2}{*}{ Smeets et al. [22] } & MF & 30 & 210 & Adequate protein pasta & S & $35 \%$ ER & $60 \%$ & $10 \%$ & $30 \%$ & - & 1.6 & 1.5 & STT a & - \\
\hline & MF & 30 & 210 & High protein pasta & S & $35 \% \mathrm{ER}$ & $45 \%$ & $25 \%$ & $30 \%$ & - & 2.0 & 1.9 & $\operatorname{STT} \mathbf{\Delta}^{\mathrm{b}}$ & - \\
\hline \multirow{2}{*}{ Sorensen, et al. [38] } & $\mathrm{M}$ & 20 & 285 & Salatrim roll & $\mathrm{s}$ & 3.2 & 97 & 19 & 40 & 2.4 & 1.7 & 1.3 & FUL ${ }^{a}$ & 3414 \\
\hline & M & 20 & 285 & Margarine roll & S & 3.2 & 97 & 19 & 40 & 2.4 & 2.1 & 1.6 & $\mathrm{FUL}^{\mathrm{b}}$ & 3331 \\
\hline \multirow{4}{*}{ Zijlstra, et al. [39] ${ }^{1}$} & M & 12 & 90 & Chocolate milk & NS & 2.0 & 67 & 13 & 16 & & & - & DTE $^{a}$, & - \\
\hline & $\mathrm{F}$ & 20 & 90 & Chocolate milk & NS & 1.6 & 53 & 11 & 13 & 7.1 & 1.5 & - & PCF ${ }^{a}$ & - \\
\hline & $\mathrm{M}$ & 12 & 90 & Chocolate custard & NS & 1.9 & 64 & 13 & 17 & & & - & DTE $\mathbf{v}^{\mathrm{b}}$ & - \\
\hline & F & 20 & 90 & Chocolate custard & NS & 1.5 & 50 & 10 & 13 & 5.3 & 1.5 & - & $\mathrm{PCF} \mathbf{v}^{\prime}$ & - \\
\hline \multirow{3}{*}{ Hlebowicz, et al. [40] } & MF & 15 & 150 & Rice pudding & NS & 1.4 & 48 & 9 & 12 & - & 1.1 & - & ND & - \\
\hline & MF & 15 & 150 & Rice pudding $+1 \mathrm{~g}$ cinnamon & NS & 1.4 & 48 & 9 & 12 & - & 1.4 & - & ND & - \\
\hline & MF & 15 & 150 & Rice pudding $+3 \mathrm{~g}$ cinnamon & NS & 1.4 & 48 & 9 & 12 & - & 1.5 & - & ND & - \\
\hline Smeets and & MF & 30 & 180 & Lunch meal & $\mathrm{s}$ & $35 \%$ ER & $60 \%$ & $10 \%$ & $30 \%$ & - & 1.6 & 2.2 & ND & - \\
\hline Westerterp-Plantenga [21] & MF & 30 & 180 & Lunch meal + red pepper & $\mathrm{s}$ & $35 \%$ ER & $60 \%$ & $10 \%$ & $30 \%$ & - & 2.1 & 4.2 & ND & - \\
\hline \multirow{4}{*}{ Veldhorst, et al. [41] } & MF & 25 & 240 & Whey custard & NS & 2.5 & 82 & 15 & 23 & - & 2.0 & - & $\operatorname{STT} \mathbf{\Delta}^{\mathrm{a}}$ & \multirow{3}{*}{2877} \\
\hline & MF & 25 & 240 & Whey custard & NS & 2.5 & 82 & 37 & 13 & - & 2.1 & - & $\mathrm{STT}^{\mathrm{b}}$ & \\
\hline & MF & 25 & 240 & Whey custard (No GMP) & NS & 2.5 & 82 & 15 & 23 & - & 1.7 & - & $\operatorname{STT} \Delta^{a}$ & \\
\hline & MF & 25 & 240 & Whey custard (No GMP) & NS & 2.5 & 82 & 37 & 13 & - & 1.9 & - & STT $^{b}$ & 3208 \\
\hline
\end{tabular}


Table 1. Cont

\begin{tabular}{|c|c|c|c|c|c|c|c|c|c|c|c|c|c|c|}
\hline \multirow{2}{*}{ Reference } & \multirow{2}{*}{ Gender } & \multirow{2}{*}{$N$} & \multirow{2}{*}{$\begin{array}{c}\text { Study } \\
\text { Duration } \\
\text { (min) }\end{array}$} & \multirow{2}{*}{ Preload Meal } & \multirow{2}{*}{ Format } & \multirow{2}{*}{$\begin{array}{l}\text { Energy } \\
\text { (MJ) }\end{array}$} & \multirow{2}{*}{$\mathrm{CHO}(\mathrm{g})$} & \multirow{2}{*}{$\begin{array}{c}\text { Protein } \\
\text { (g) }\end{array}$} & \multirow{2}{*}{ Fat (g) } & \multicolumn{3}{|c|}{ Fold Change } & \multicolumn{2}{|c|}{ Appetite Outcomes } \\
\hline & & & & & & & & & & CCK & GLP-1 & PYY & Sensation & FI (kJ) \\
\hline \multirow{2}{*}{ Veldhorst, et al. [42] } & MF & 25 & 240 & Casein custard & NS & 2.5 & 82 & 15 & 23 & - & 1.5 & - & FUL ${ }^{a}$ & 3133 \\
\hline & MF & 25 & 240 & Casein custard & NS & 2.5 & 82 & 37 & 13 & - & 1.4 & - & FULı ${ }^{b}$ & 3080 \\
\hline \multirow{2}{*}{ Veldhorst, et al. [43] } & MF & 25 & 240 & Soy custard & NS & 2.5 & 82 & 15 & 23 & - & 1.5 & - & STT ${ }^{a}$ & 3090 \\
\hline & MF & 25 & 240 & Soy custard & NS & 2.5 & 82 & 37 & 13 & - & 1.5 & - & $\mathrm{STT}^{\mathrm{b}}{ }^{\mathrm{b}}$ & 3212 \\
\hline \multirow{3}{*}{ Nieuwenhuizen, et al. [44] } & MF & 24 & 240 & $\alpha$-lactalbumin custard & NS & 2.5 & 82 & 15 & 23 & - & 2.0 & - & ND & 2650 \\
\hline & MF & 24 & 240 & Gelatine custard & NS & 2.5 & 82 & 15 & 23 & - & 1.9 & - & ND & 2560 \\
\hline & MF & 24 & 240 & Gelatine custard + TRP & NS & 2.5 & 82 & 15 & 23 & - & 2.0 & - & ND & 2610 \\
\hline \multirow{4}{*}{ Kohnke, et al. [45] } & MF & 11 & 360 & Sandwich & $\mathrm{S}$ & 2.3 & 34 & 12 & 40 & 2.1 & - & - & - & - \\
\hline & MF & 11 & 360 & Sandwich $+50 \mathrm{~g}$ thylakoid & $\mathrm{s}$ & 3.0 & 45 & 35 & 45 & 2.0 & - & - & - & - \\
\hline & MF & 11 & 360 & Sandwich +25 g thylakoid & $\mathrm{s}$ & 2.6 & 40 & 24 & 42 & 1.3 & - & - & - & - \\
\hline & MF & 11 & 360 & Sandwich $+25 \mathrm{~g}$ delipidated thylakoid & $\mathrm{s}$ & 2.6 & 39 & 24 & 41 & 1.4 & - & - & - & - \\
\hline \multirow{4}{*}{ Juvonen, et al. [46] } & MF & 20 & 180 & Pudding & NS & 1.3 & 57 & 4 & 4 & - & - & 1.1 & ND & ND \\
\hline & MF & 20 & 180 & Pudding with wheat bran & NS & 1.3 & 55 & 6 & 4 & - & - & 1.1 & ND & ND \\
\hline & MF & 20 & 180 & Pudding with oat bran & NS & 1.3 & 53 & 8 & 4 & - & - & 1.1 & ND & ND \\
\hline & MF & 20 & 180 & Pudding with wheat and oat bran & NS & 1.3 & 57 & 7 & 4 & - & - & 1.1 & ND & ND \\
\hline \multirow{3}{*}{ Juvonen, et al. [47] } & $\mathrm{M}$ & 8 & 240 & Viscous casein beverage & NS & 1.0 & 4 & 54 & 0.5 & - & 1.9 & - & ND & - \\
\hline & $\mathrm{M}$ & 8 & 240 & Casein gel beverage & NS & 1.0 & 4 & 54 & 0.5 & - & 1.4 & - & ND & - \\
\hline & M & 8 & 240 & Whey beverage & NS & 1.0 & 4 & 52 & 0.3 & - & 3.6 & - & ND & - \\
\hline \multirow{4}{*}{ Brennan, et al. [48] } & $\mathrm{M}$ & 16 & 240 & High fat pasta & $\mathrm{s}$ & 3.8 & 68 & 34 & 55 & 1.2 & - & 1.8 & - & $4156^{a, b}$ \\
\hline & $\mathrm{M}$ & 16 & 240 & High protein pasta & $\mathrm{s}$ & 3.8 & 68 & 101 & 25 & 1.4 & - & 1.6 & - & $3890^{\mathrm{a}}$ \\
\hline & $\mathrm{M}$ & 16 & 240 & High $\mathrm{CHO}$ low protein pasta & $\mathrm{s}$ & 3.8 & 135 & 23 & 30 & 1.6 & - & 1.7 & - & $4509^{\mathrm{b}}$ \\
\hline & M & 16 & 240 & Adequate protein pasta & $\mathrm{s}$ & 3.8 & 90 & 68 & 30 & 1.5 & - & 1.8 & - & $4533^{\mathrm{b}}$ \\
\hline \multirow{3}{*}{ Kim, et al. [49] } & $\mathrm{F}$ & 10 & 180 & Regular breakfast meal & $\mathrm{s}$ & 2.1 & 77 & 26 & 11 & - & - & 0.8 & - & - \\
\hline & $\mathrm{F}$ & 10 & 180 & High protein breakfast meal & $\mathrm{s}$ & 2.1 & 39 & 64 & 11 & - & - & 1.1 & - & - \\
\hline & $\mathrm{F}$ & 10 & 180 & High fat breakfast meal & $\mathrm{s}$ & 2.1 & 39 & 26 & 28 & - & - & 0.9 & - & - \\
\hline \multirow[t]{2}{*}{ Zhu, et al. [50] } & M & 19 & 180 & Chicken soup with solid vegetable & NS & 1.2 & 37 & 10 & 11 & 0.5 & - & - & $\begin{array}{l}\text { FUL a, } \\
\text { PWF }{ }^{a}\end{array}$ & $551.5 \mathrm{~g}$ \\
\hline & M & 19 & 180 & Chicken soup with liquid vegetable & NS & 1.2 & 37 & 10 & 11 & 0.8 & - & - & $\begin{array}{l}\text { FUL } \mathbf{\Delta}^{\mathrm{b}}, \\
\text { PWF } \mathbf{b}^{\mathrm{b}}\end{array}$ & $545.6 \mathrm{~g}$ \\
\hline \multirow{3}{*}{ van der Klaauw, et al. [51] } & MF & 8 & 270 & High protein pancakes & $\mathrm{s}$ & 1.7 & 20 & 60 & 9 & - & 1.5 & 1.4 & ND & 4280 \\
\hline & MF & 8 & 270 & High CHO pancakes & $\mathrm{s}$ & 1.7 & 60 & 20 & 9 & - & 1.4 & 1.2 & ND & 4845 \\
\hline & MF & 8 & 270 & High fat pancakes & $\mathrm{s}$ & 1.7 & 20 & 20 & 27 & - & 1.4 & 1.0 & ND & 4251 \\
\hline
\end{tabular}


Table 1. Cont.

\begin{tabular}{|c|c|c|c|c|c|c|c|c|c|c|c|c|c|c|}
\hline \multirow{2}{*}{ Reference } & \multirow{2}{*}{ Gender } & \multirow{2}{*}{$N$} & \multirow{2}{*}{$\begin{array}{c}\text { Study } \\
\text { Duration } \\
\text { (min) }\end{array}$} & \multirow{2}{*}{ Preload Meal } & \multirow{2}{*}{ Format } & \multirow{2}{*}{$\begin{array}{c}\text { Energy } \\
\text { (MJ) }\end{array}$} & \multirow{2}{*}{$\mathrm{CHO}(\mathrm{g})$} & \multirow{2}{*}{$\begin{array}{l}\text { Protein } \\
\text { (g) }\end{array}$} & \multirow{2}{*}{ Fat $(g)$} & \multicolumn{3}{|c|}{ Fold Change } & \multicolumn{2}{|c|}{ Appetite Outcomes } \\
\hline & & & & & & & & & & CCK & GLP-1 & PYY & Sensation & FI (kJ) \\
\hline Little, et al. [52] & MF & 16 & 180 & Ensure Plus ${ }^{\circledR}$ Nutrient Drinks & NS & 3.1 & 100 & 32 & 25 & 2.8 & - & 1.6 & - & 3305 \\
\hline Zhu and Hollis [53] & M & 8 & 180 & Tomato basil soup & NS & 1.6 & 62 & 4 & 13 & 1.1 & - & - & - & - \\
\hline \multirow{4}{*}{ Ohlsson, et al. [54] } & MF & 19 & 300 & Breakfast + yoghurt ( $35 \mathrm{~g}$ oat oil) & NS & 3.1 & 65 & 19 & 43 & 6.0 & 2.1 & 1.7 & $\operatorname{STT} \mathbf{\Delta}^{\text {a } 3}$ & ND \\
\hline & MF & 19 & 300 & Breakfast + yoghurt $(0 \mathrm{~g}$ oat oil $)$ & NS & 2.9 & 65 & 19 & 39 & 5.3 & 1.8 & 1.7 & $\mathrm{STT}^{\mathrm{b}}$ & ND \\
\hline & $\mathrm{F}$ & 14 & 300 & Breakfast + milk (14 g oat oil) & NS & 2.9 & 65 & 19 & 39 & 6.1 & 3.5 & 2.2 & - & ND \\
\hline & $\mathrm{F}$ & 14 & 300 & Breakfast + milk (1.8 g oat oil) & NS & 2.9 & 66 & 19 & 39 & 3.7 & 3.4 & 2.1 & - & ND \\
\hline \multirow{2}{*}{ Chungchunlam, et al. [55] } & $\mathrm{F}$ & 18 & 120 & Maltodextrin preload drinks & NS & 2.9 & 72 & 3 & 3 & 1.2 & 1.5 & 1.2 & ND & $2442^{a}$ \\
\hline & $\mathrm{F}$ & 18 & 120 & Whey preload drinks & NS & 2.9 & 26 & 46 & 3 & 1.3 & 1.5 & 1.1 & ND & $2920^{\mathrm{b}}$ \\
\hline \multirow[t]{3}{*}{ Bligh, et al. [56] } & M & 19 & 180 & Reference meal & S & 1.6 & 57 & 13 & 11 & - & 1.8 & 1.0 & $\begin{array}{l}\text { HGR }^{a}{ }^{\prime} \\
\text { FUL }^{a^{\prime}} \\
\text { DTE }^{\text {a }}\end{array}$ & - \\
\hline & M & 17 & 180 & Palaeolithic meal 1 & $\mathrm{~s}$ & 2.3 & 65 & 41 & 18 & - & 1.5 & 1.1 & $\begin{array}{l}\text { HGR } \boldsymbol{b}^{\mathrm{b}} \\
\text { FUL } \mathrm{b}^{\prime} \\
\text { DTE }{ }^{\prime}{ }^{\prime}\end{array}$ & - \\
\hline & M & 19 & 180 & Palaeolithic meal 2 & $\mathrm{~s}$ & 1.6 & 66 & 16 & 11 & - & 1.2 & 1.1 & $\begin{array}{l}\text { HGR } \boldsymbol{v}^{\mathrm{b}} \\
\text { FULム } \mathrm{b}^{\mathrm{b}} \\
\text { DTE }{ }^{\prime}{ }^{\prime}\end{array}$ & - \\
\hline \multirow{2}{*}{ Clamp, et al. [57] } & M & 10 & 180 & Milkshake & NS & 4.7 & 56 & 11 & 98 & - & - & 1.5 & ND & $533.7 \mathrm{~g}$ \\
\hline & M & 10 & 180 & Milkshake & NS & 4.7 & 56 & 11 & 98 & - & - & 1.4 & ND & $509.1 \mathrm{~g}$ \\
\hline Hutchison, et al. [58] & M & 20 & 180 & $70 \mathrm{~g}$ whey protein drink & NS & 1.2 & - & - & - & 1.9 & 1.7 & - & - & 4176 \\
\hline \multirow[t]{2}{*}{ Gonzalez-Anton, et al. [59] } & MF & 30 & 240 & Cereal-based bread & $\mathrm{s}$ & 1.1 & 38 & 13 & 4 & - & 1.7 & - & $\begin{array}{l}\text { PCF }{ }^{a} \text {, } \\
\text { STT }{ }^{a}\end{array}$ & 4184 \\
\hline & MF & 30 & 240 & White bread & S & 1.0 & 47 & 7 & 4 & - & 1.9 & - & $\begin{array}{l}\mathrm{PCF}^{\mathrm{b}} \\
\text { STT }^{\mathrm{b}}\end{array}$ & 4268 \\
\hline \multirow{3}{*}{ Overduin, et al. [60] } & MF & 10 & 240 & Sucrose control preload & NS & 1.6 & 55 & 15 & 13 & - & 1.6 & 1.3 & $\mathrm{HGR}^{\mathrm{a}}$ & ND \\
\hline & MF & 10 & 240 & Isovolumic erythritol preload & NS & 1.2 & 29 & 14 & 29 & - & 2.3 & 1.7 & $\mathrm{HGR}^{\mathrm{a}}$ & ND \\
\hline & MF & 10 & 240 & Isocaloric erythritol preload & NS & 1.6 & 39 & 26 & 28 & - & 2.4 & 1.5 & HGR ${ }^{b}$ & ND \\
\hline
\end{tabular}

Appetite outcomes that are statistically different from each other are indicated by different superscript letters, i.e., a and b. Only subjective appetite outcomes that are statistically different when expressed in terms of Area under the Curve (AUC) are reported, unless otherwise specified. ${ }^{1}$ Males and females received preload meal with different macronutrient composition but results for fold change were combined. ${ }^{2}$ The difference in satiety was significant from $\mathrm{T}=0 \mathrm{~min}$ to $\mathrm{T}=90 \mathrm{~min}$ only. ${ }^{3}$ The difference in satiety was significant for the female subgroup only. Abbreviations and symbols: $\mathrm{M}=$ Male, $\mathrm{F}=$ Female, $\mathrm{MF}=$ Mixed gender, $\mathrm{S}=$ Solid, NS = Non-solid, $\mathrm{CHO}=$ Carbohydrate, ER = Energy requirement, FI = Mean food intake reported in the unit of kJ except a few reported in the unit of $\mathrm{g}$ where specified, ND = No significant difference, $\mathrm{FUL}=$ Fullness, $\mathrm{STT}=$ Satiety, $\mathrm{STF}=$ Satisfaction, HGR $=$ Hunger, DTE $=$ Desire to eat, PCF

$=$ Prospective consumption of food, $\mathrm{PWF}=$ Preoccupation with food, $\mathbf{\Lambda}=$ Significant increase, $\mathbf{v}=$ Significant decrease, $-=$ No data, not reported, no comparison or not assessed. 
INFUSION consisted of 34 intravenous infusion interventions published in 18 articles (Table 2). All studies were randomised controlled trials. Each study consisted of 1 to 6 interventions, excluding the control (placebo saline infusion). Eight interventions (24\%) had a combination of genders, whereas 25 $(74 \%)$ interventions enrolled male participants only and $1(3 \%)$ intervention enrolled female participants only. Notably, male were over-represented in INFUSION. The median sample size of INFUSION was 10 (range: 6-24). There were a total of 8 interventions which infused CCK, 11 interventions which infused GLP-1 and 15 interventions infused PYY.

The methodology of INFUSION was less standardised than DIET. Variability included infusion duration and presence of oral preload. Eighteen (53\%) interventions infused from the fasting state until completion of the outcome meal, whereas $13(38 \%)$ interventions stopped the infusion prior to the meal. The outcome meal was not part of the procedure in $3(9 \%)$ interventions. The median infusion duration was $90 \mathrm{~min}$ (range: $10-240 \mathrm{~min}$ ). In $63 \%$ of the CCK infusions, and in $46 \%$ of the GLP-1 infusions, an oral preload was given prior to or during the infusion. None of the PYY infusions had an oral preload. Gastric cues were believed to play a role in lowering the threshold concentration at which CCK exhibits its physiological effects on satiety. Banana and water were the most common dietary preload in CCK infusion studies, because these preloads were not found to induce the secretion of GI peptides significantly $[61,62]$. All peptide infusion studies had placebo saline infusion as a control, but the results are not presented in this review. Generally, DIET had a larger sample size, were of longer duration and followed a more standardised protocol than INFUSION.

\section{3. $C C K$}

CCK is a group of molecules consisting of various molecular forms, named after their peptide chain length. CCK- 8 and CCK-33 have 8 and 33 amino acids respectively. They are 2 of the most common molecular forms measured in appetite studies, especially in INFUSION. In this review, all forms of CCK were grouped into one analysis, as the form of CCK being assessed was not made clear in most studies. The range of CCK baseline concentration (Figure 3a) was similar between DIET (0.17-8.30 pM) and INFUSION (0.45-7.90 pM), as expected. However, the weighted means had a small but significant difference between DIET (1.72 pM, 95\% CI: 1.59-1.84 pM) and INFUSION $(2.38 \mathrm{pM}, 95 \%$ CI: $1.95-2.81 \mathrm{pM})(p<0.01)$. Despite the wide range, it is noticeable from Figure 3a that most of the data was distributed below $4.00 \mathrm{pM}$ for both DIET and INFUSION. The range of CCK $\mathrm{C}_{\max }$ (Figure $\left.3 b\right)$ was much narrower for DIET (0.90-9.40 pM) than INFUSION (2.55-45.40 pM). The weighted mean was also significantly lower for DIET (3.34 pM, 95\% CI: 3.17-3.51 pM) than INFUSION (17.77 pM, 95\% CI: $15.07-20.46$ pM) $(p<0.01)$. Six of 8 INFUSION interventions resulted in CCK $\mathbf{C}_{\max }$ levels unachievable by DIET interventions. The fold change of CCK (Figure 3c) ranged from 0.51 -fold to 7.85-fold for DIET, much narrower than INFUSION, which ranged from 3.60-fold to 37.80-fold. The weighted mean was also significantly lower for DIET (2.98-fold, 95\% CI: 2.83-3.13-fold) than INFUSION (10.96-fold, 95\% CI: 8.68-3.23-fold) $(p<0.01)$. Attention was given to two DIET articles that reported a 7.85- and 7.06-fold increase in CCK [34,39]. However, the form of CCK analysed was CCK-8, had low baseline concentration (range: $0.17-0.34 \mathrm{pM}$ ) and a relatively low absolute $\mathbf{C}_{\max }$ (range: 0.90-1.57 pM). Surprisingly, these two studies did not show greater fold change in CCK concentrations when compared to their active-controlled interventions (7.85-fold vs. 3.94-fold, 7.06-fold vs. 5.29-fold) significantly decreased subjective appetite sensation and food intake. 
Table 2. Peptide infusion (INFUSION) studies in lean men and women.

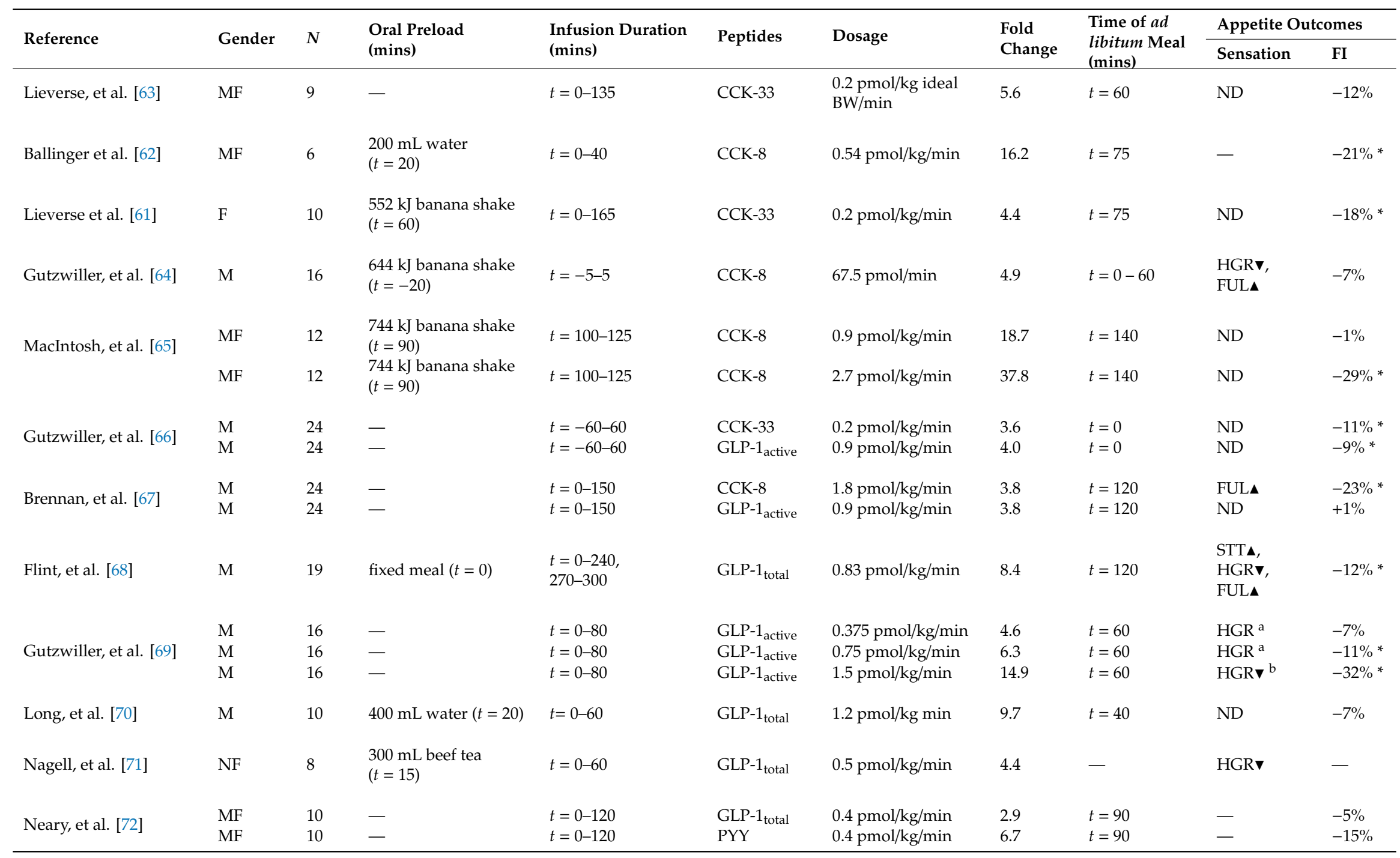


Table 2. Cont.

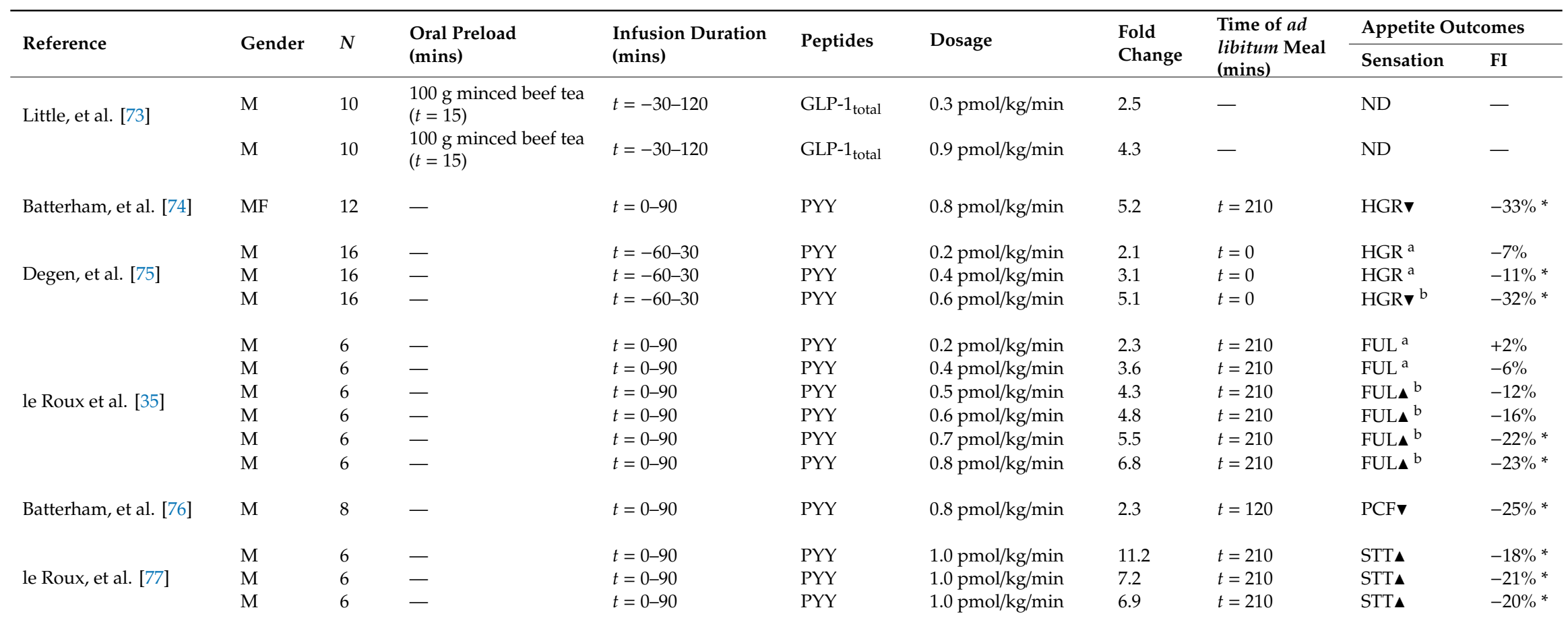

In some studies, a small oral preload $(<1 \mathrm{MJ})$ was given to participants. The time reported refers to the time point at which oral preload was given, no information about the time given to consume the preload completely was found in the original articles. The time reported for the infusion duration represents the starting and ending time point of the peptide infusion, the study may continue after the infusion until ad libitum meal. The time reported for ad libitum meal represents the time point at which the meal was given to participants; no information about the time given to consume the meal was found in original articles for most studies. Appetite outcomes that are statistically different from each other are indicated by different superscript letters, i.e., a and b. Only subjective appetite outcomes that are statistically different when expressed in terms of Area under the Curve (AUC) are reported, unless otherwise specified. Effects on food intake was compared with placebo control and reported as increase/decrease in percentage energy intake. Abbreviations and symbols: M = Male, F = Female, MF $=$ Mixed gender, FI = Food intake, ND = No significant difference, FUL = Fullness, STT = Satiety, HGR = Hunger, PCF = Prospective consumption of food, $\mathbf{\Delta}=$ Significant increase when compared to placebo control, $\mathbf{v}=$ Significant decrease when compared to placebo control, ${ }^{*}=$ Food intake significantly different from placebo control, $-=$ Oral preload, ad libitum meal, or subjective appetite assessment was not included in the study. 


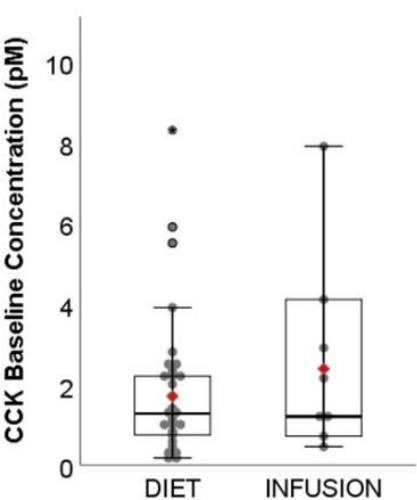

(a)

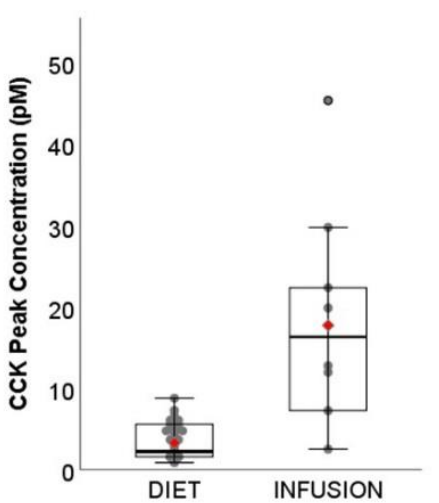

(b)

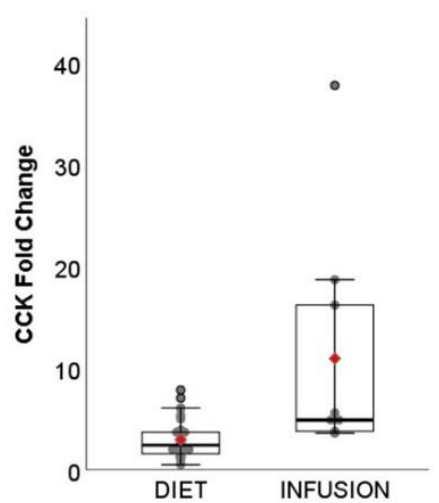

(c)

Figure 3. Boxplots showing the (a) baseline concentration, (b) $\mathbf{C}_{\max }$, peak concentration, and (c) fold change of CCK between DIET $(\mathrm{N}=620, \mathrm{~K}=39)$ and INFUSION $(\mathrm{N}=98, \mathrm{~K}=8)$. The weighted means were significantly different between DIET and INFUSION for all $(p<0.01$, all).

\subsection{GLP-1}

There are two forms of GLP-1, active and total. GLP-1 is secreted in active form into circulation, where it is highly susceptible to deactivation by dipeptidyl peptidase IV (DPP-IV) enzyme. Active GLP-1 has a very short half-life of $1 \mathrm{~min}$ [78,79]. In this review, GLP-1 is grouped individually into active and total GLP-1 for the assessment of baseline and $\mathbf{C}_{\max }$, and pooled together when assessing fold change. This method, which assumes that relative increase in active GLP-1 is equal to relative increase in total GLP-1, also allowed comparison with the prior review [18]. The range of total GLP-1 baseline concentration (Figure 4a) was much greater for DIET (range: 9.40-40.60 pM) than INFUSION $(10.00-21.50 \mathrm{pM})$. This was unexpected. The weighted mean was also significantly higher for DIET (17.78 pM, 95\% CI: 17.25-18.31 pM) than INFUSION (12.48 pM, 95\% CI: 11.52-13.44 pM) $(p<0.01)$. A DIET study conducted by Dougkas and Ostman [20] reported that total GLP-1 baseline concentration ranged between $105.90 \mathrm{pM}$ and $162.70 \mathrm{pM}$, at least 15 standard deviations greater than the weighted mean in this analysis. They were being removed from our analysis as data may be unreliable (see Figure 2). The range of total GLP-1 $\mathrm{C}_{\max }$ (Figure $4 \mathrm{~b}$ ) for DIET (19.40-98.60 pM) was similar to that of INFUSION (25.70-126.00 pM). However, the weighted mean was significantly lower for DIET (32.59 pM, 95\% CI: 31.27-33.91 pM) than INFUSION (69.30 pM, 95\% CI: 61.37-77.24 pM) $(p<0.01)$.

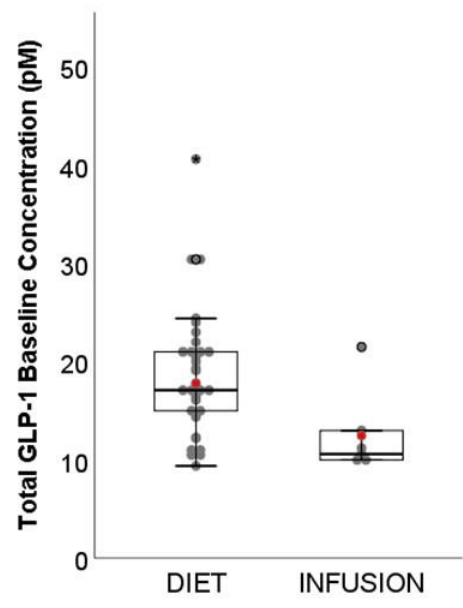

(a)

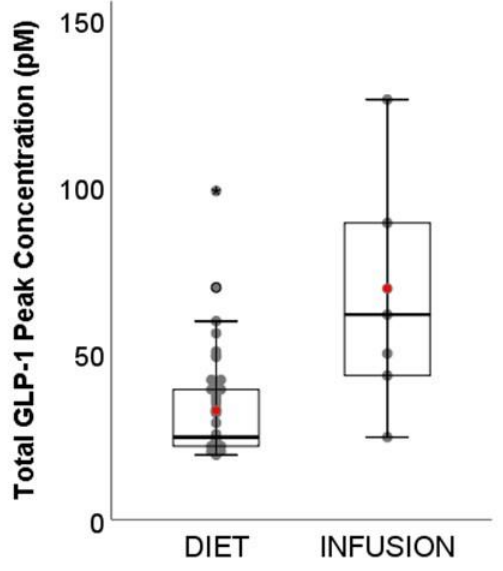

(b)

Figure 4. Boxplots showing the (a) baseline concentration, and (b) $C_{\max }$, peak concentration of total GLP-1 between DIET $(\mathrm{N}=479, \mathrm{~K}=37)$ and INFUSION $(\mathrm{N}=67, \mathrm{~K}=6)$. The weighted means were significantly different between DIET and INFUSION for all $(p<0.01$, all). 
The range of the active GLP-1 baseline concentration (Figure 5a) for DIET was 3.60-13.00 pM, whereas the range for INFUSION was $0.60-7.00 \mathrm{pM}$. Similar to total GLP-1 baseline concentration, the weighted mean was significantly higher for DIET (4.77 pM, 95\% CI: 4.68-4.86 pM) than INFUSION (1.43 pM, 95\% CI: 0.99-1.87 pM). This was again unexpected. Notably, 22 of 29 DIET interventions assessing active GLP-1 were conducted by Westerterp and colleagues [21,22,41-44]; whereas 4 of 5 INFUSION interventions were conducted by Gutzwiller and colleagues [66,69]. Results reported by the same group of researchers had reasonably consistent baseline concentration. The range of active GLP-1 $\mathrm{C}_{\max }$ for DIET was 6.10-25.00 pM, whereas the range for INFUSION was 2.40-35.00 pM (Figure $5 \mathrm{~b}$ ). The weighted means were not significantly different between DIET (8.73 pM, 95\% CI: 8.49-8.97 pM) and INFUSION ( $8.67 \mathrm{pM}, 95 \% \mathrm{CI}: 6.46-10.87 \mathrm{pM})(p=0.96)$. Although ranges and means were similar, the higher baseline concentration reported in DIET should not be overlooked during interpretation.

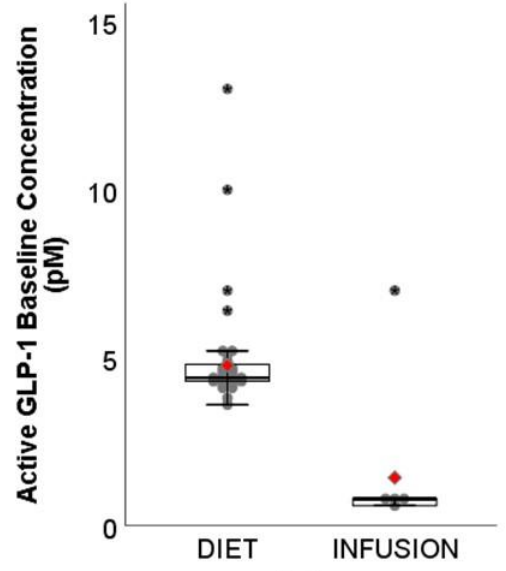

(a)

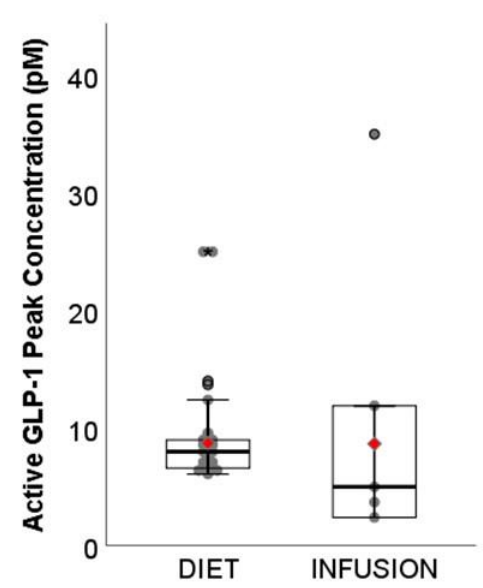

(b)

Figure 5. Boxplots showing the (a) baseline concentration, and (b) $C_{\max }$, peak concentration of active GLP-1 between DIET ( $N=683, K=29)$ and INFUSION $(N=81, K=5)$. The weighted means were significantly different between DIET and INFUSION for (a) baseline concentration $(p<0.01)$, but not (b) $\mathbf{C}_{\max }$, peak concentration $(p=0.96)$.

The range of GLP-1 fold change (total and active combined) (Figure 6) was much narrower for DIET (1.09-3.63-fold) than INFUSION (2.50-14.90-fold). The weighted mean was also significantly lower for DIET (1.85-fold, 95\% CI: 1.82-1.89-fold) than INFUSION (6.29 pM, 95\% CI: 5.72-6.86 pM) ( $p<$ 0.01). Sanggaard and colleagues [29] reported the highest GLP-1 fold change among DIET (3.39-fold and 3.69-fold), however, the preload energy content was 3.7 MJ and 4.1 MJ, respectively, approximately $2 \times$ greater than median energy intake $(1.8 \mathrm{MJ})$ in this review. Also notable was the DIET study conducted by Juvonen and colleagues [47], which showed greater fold change in GLP-1 (3.57-fold) following consumption of whey protein beverage than 2 casein protein beverages (1.92-fold and 1.40-fold). Despite greater fold change, there was no significant difference in subjective appetite sensations.

\subsection{PYY}

Unexpectedly, the range of PYY baseline concentration (Figure 7) for DIET (2.20-97.00 pM) was greater than INFUSION (8.30-28.70 pM). The weighted mean was also significantly higher for DIET (32.28 pM, 95\% CI: 30.27-34.29 pM) than INFUSION (76.41 pM, 95\% CI: 70.13-82.69 pM) $(p<0.01)$. The range of PYY $C_{\max }$ was greater for DIET (3.30-170.00 pM) than INFUSION (24.90-147.90 pM). The weighted mean was also significantly lower for DIET (47.72 pM, 95\% CI: 44.86-50.58 pM) than INFUSION (76.41 pM, 95\% CI: 70.13-82.69 pM) ( $p<0.01)$. Two DIET studies [46,54], which reported very high $\mathrm{C}_{\max }$ (range: $100.00-170.00 \mathrm{pM}$ ) also reported very high baseline concentrations (range: 77.00-97.00 pM). The range of PYY fold change was lower for DIET (0.78-4.17-fold) than INFUSION (2.13-11.23-fold). The weighted mean was also significantly lower for DIET (1.82-fold, $95 \%$ CI: 
1.77-1.88-fold) than INFUSION (4.78 pM, 95\% CI: 4.40-5.16 pM) $(p<0.01)$. le Roux and colleagues [35] demonstrated that secretion of PYY increased with energy consumption. Another noteworthy study involved the consumption of $1030 \mathrm{mg}$ of red pepper (containing 80,000 Scoville Heat Units of capsaicin) with a lunch meal, which led to a 4.11-fold increase in PYY secretion, compared to 2.17-fold for placebo [21]. However, no statistical difference in subjective appetite sensations was reported in this study.

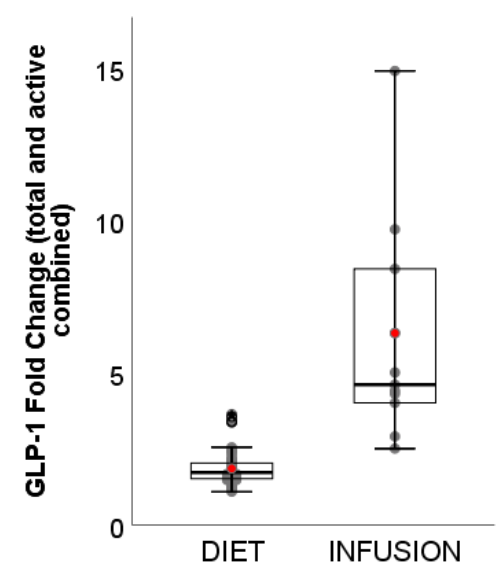

Figure 6. Boxplots showing fold change of GLP-1 (total and active) between DIET $(\mathrm{N}=1162, \mathrm{~K}=66$ ) and INFUSION $(\mathrm{N}=152, \mathrm{~K}=11)$. The weighted means were significantly different between DIET and INFUSION $(p<0.01)$.

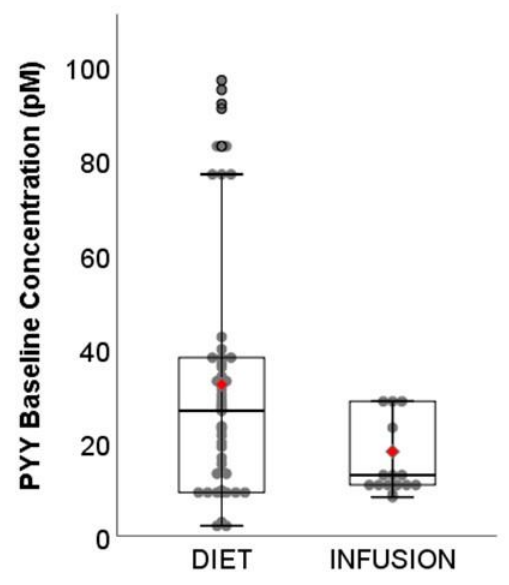

(a)

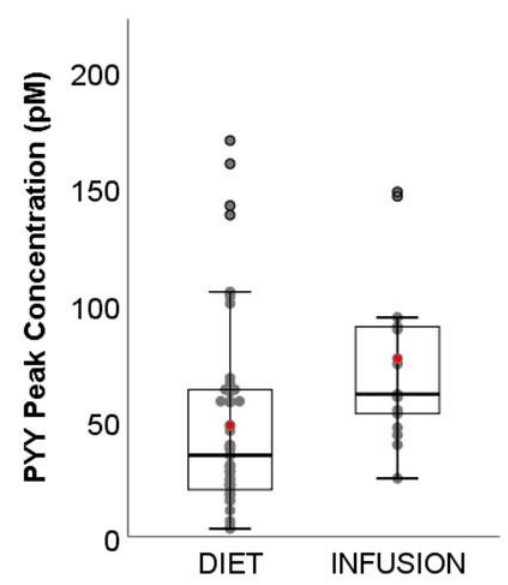

(b)

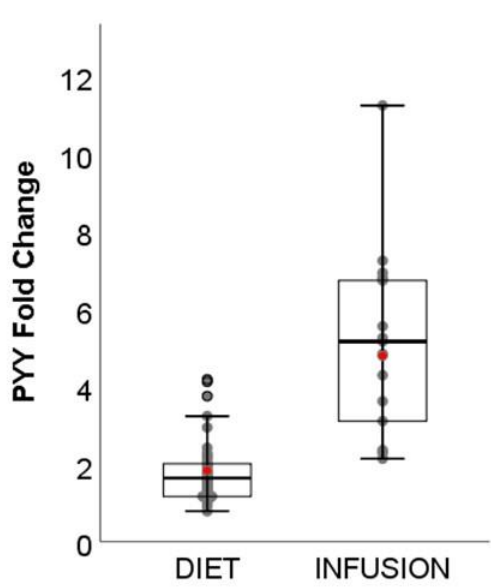

(c)

Figure 7. Boxplots showing (a) baseline concentration, (b) $\mathbf{C}_{\max }$, peak concentration, and (c) fold change of PYY between DIET ( $\mathrm{N}=804, \mathrm{~K}=50)$ and INFUSION $(\mathrm{N}=132, \mathrm{~K}=15)$. The weighted means were significantly different between DIET and INFUSION for all $(p<0.01$, all).

\section{Discussion}

Despite a long history of appetite research, a number of fundamental questions on the physiological regulation of food intake remain unanswered. One key question is whether peptides secreted from the GI tract following consumption of a meal are reliable biomarkers of hunger, fullness and other appetite-related responses, or more importantly subsequent food intake. Our review of the literature concludes that causal links between food consumption and the appearance of GI-secreted peptides in peripheral circulation at concentrations likely to drive changes in appetite response and eating behaviour remain to be demonstrated. As yet, no single peptide or group of peptides can be measured in blood to predict how hungry you feel or what and how much you are likely to eat at your next meal. 
This review presents data on baseline and peak concentration in addition to fold change in 3 key circulating peptides, i.e., CCK, GLP-1 and PYY, in response to both peptide infusion and consumption of a meal in healthy adults. The great variability in baseline concentration was unexpected since we included only studies of lean and healthy adults, and as a result, it was not of value to review absolute peak concentration between studies. Whilst the range of peak concentration in the dietary studies provided valuable information regarding the physiological postprandial range, relative change between baseline and peak concentration (fold change) allowed comparison between studies. An important finding of this review was that the postprandial fold change of CCK, GLP-1 and PYY following food intake was consistently lower for all peptides when compared to that observed following exogenous peptide infusion.

\subsection{Exploring the Relationship between Circulating GI Peptides and Appetite Outcomes}

Based on the existing literature, this current review found no clear evidence that the postprandial fold change in peripheral circulating GI peptide concentrations in response to an energy bolus of at least $1 \mathrm{MJ}$ was linked to appetite sensation in lean and healthy adults. A linear relationship between fold change in GI peptides and ad libitum energy intake could not be established in dietary preload studies. Consequently, the diet-induced increase in GI peptides was not consistent with appetite outcomes. Based on the peptide infusion studies, the minimum fold change reported to decrease ad libitum energy intake for each of CCK, GLP-1 and PYY was 3.6, 4.0 and 3.1-fold, respectively. In other words, infusing GI peptides to meet these 'thresholds' may result in significant suppression of ad libitum energy intake when compared to saline infusion. In contrast, no evidence of significant suppression of ad libitu energy intake was found when the infusion was insufficient to meet these 'thresholds'. Only $29 \%$ of reported CCK concentrations in dietary studies met this 'threshold' fold change, whilst this was even lower at $0 \%$ for GLP-1 and $8 \%$ for PYY. This observation confirms that it is very challenging to elevate postprandial circulating GI peptides to meet the 'threshold' identified from peptide infusion studies using a low-energy preload. The energy content of preloads in this review ranged predominantly between 1 to $4.7 \mathrm{MJ}$ (outliers 8.4, $12.5 \mathrm{MJ}$ ), with mean preload of $2.3 \mathrm{MJ}$. However, the 'threshold' could potentially be lowered as had been well demonstrated by Lieverse and colleagues. They showed that gastric distention can lower the CCK threshold to induce a satiety response $[61,63]$. Hence, the 'actual threshold' of GI peptides could potentially be lower than those that we propose in this review, based on the following two arguments.

Firstly, the 'threshold' suggested in this review was based on the 'single-peptide approach', which investigated the fold change of a single peptide as an independent factor for ad libitum energy intake. Most peptide infusion studies were carried out by infusing a single peptide at a time. While this approach is useful for excluding confounders, the interaction between 2 or more GI peptides should not be overlooked. Some peptide infusion studies have infused 2 peptides simultaneously $[66,67,72,80]$. There was some evidence of peptides acting additively or synergistically $[72,80,81]$, providing a strong rationale to measure 3 peptides in a single dietary study. Unfortunately, the data to date is too scarce to draw any conclusions.

Secondly, intravenous GI peptide infusion into systemic circulation may bypass a potentially significant paracrine or neurocrine stimulation pathway, which happens around the site of secretion and vagal afferent nerves, before hepatic clearance takes place [82]. Based on the data from peptide infusion studies, these GI peptides are potent endocrine hormones; however, their full potency may lie beyond endocrine activities. There is evidence that CCK acts via paracrine pathway before being diluted in the systemic circulation, as shown in an early study where hepatic-portal infusion of CCK was less efficient than intraperitoneal infusion of CCK in suppressing energy intake [83]. Also, it has been proposed that GLP-1 triggers a satiety response by activating GLP-1 receptors near the site of secretion before entering the systemic circulation, although the endocrine effect of GLP-1 was also acknowledged [84]. In contrast to CCK and GLP-1, much research on PYY has focused on $Y_{2}$ receptors in the central nervous system [12]. 
These arguments raise the possibility that the 'threshold' observed in in this review may be too high. Irrespective, there is insufficient evidence to link the circulating GI peptides to appetite response at a lower circulating concentration.

\subsection{Implications for the Development of Satiety-Enhancing Novel Food Products}

Developing satiety-enhancing novel food products by targeting the mechanisms of GI peptide secretion requires delivery of macronutrients into the intestine. The ability of available carbohydrate, protein and fat to induce secretion of GI peptides has been characterised in studies which infused single nutrients into different regions of the intestinal tract [2-7]. However, drawing implications on the dose-dependent secretion of GI peptides based on these findings has been unsuccessful. For example, despite the satiating effect of dietary protein, which is well supported through dietary studies [48,85], no linear relationship was observed between protein content and GI peptide response in our current review. The considerable variability in macronutrient composition, energy density, food format (solid or liquid), texture and other preload variables may in part explain this. It is also noteworthy that GI peptide secretion can be modified by unavailable carbohydrate, i.e., dietary fibre [36,86-88]. Dietary fibre in turn modifies the delivery of available carbohydrate, protein and fat to the nutrient-sensing cells, and is well known for its satiating effect $[89,90]$. Strategies for delivering undigested nutrients into the distal intestine in order to stimulate secretion of GLP-1 and PYY appear to be extremely challenging to deploy [2]. Unlike postprandial changes in peptides such as insulin, postprandial changes in the GI-derived 'satiety' peptides are more subtle and difficult to predict based on existing studies.

\subsection{Limitations and Recommendations for Future Studies}

One of the limitations of our findings is that this is not a systematic review. Although reporting PubMed as the sole database may have resulted in fewer studies, the main outcome of the analysis is unambiguous and unlikely to change significantly with the addition of further postprandial studies.

Secondly, total concentration of circulating GI peptides over the postprandial period, reported as AUC, would be a more preferable measure when comparing differential peptide responses within studies. However, since studies differed in duration from 30 to $480 \mathrm{~min}$, AUC was not an appropriate measure to use; hence, baseline and peak concentration were analysed. Future reviews could investigate the effect of peptide concentration prior to the ad libitum outcome meal on the energy intake.

Thirdly, although our current review showed poor associations between circulating concentration of single GI peptides and appetite outcomes, it is possible that measuring multiple peptides CCK, GLP-1 and PYY concurrently may be more informative and improve the understanding of additive or synergistic mechanisms of peptides in the regulation of appetite. This could potentially lead to profiling an appetite-related biomarkers 'fingerprint'. Studies which investigate longer-term circulating peptide concentrations over periods of $24 \mathrm{~h}$ [91] or several days may also be more informative than single meal outcomes.

The potential role of phenotypic or individual variability on GI peptides profile and satiety responses has been presented in previous reviews [14,82,92]. Hence, finally, since our current review targeted only a healthy, lean adult population, our findings are not applicable to obese populations which may have a unique GI peptides profile, although notable this is not without conflicting results [53]. Clamp and colleagues [57] recently demonstrated that obese individuals who habitually consume a high-fat diet had a lower postprandial PYY response than lean individuals, yet similar ad libitum energy intake between the two groups. Giezenaar and colleagues also recently demonstrated that young men had greater postprandial GLP-1 and PYY, accompanied by a greater suppression in $a b$ lib energy intake than young women [93]; but lower postprandial CCK than old men, accompanied by a lesser suppression in ad libitum energy intake [5]. Collectively, the variable appetite response to an identical preload meal is an emerging concept known as the satiety phenotype [94]. 


\section{Conclusions}

Long-term weight loss remains an unattainable goal for many individuals, despite the considerable resource invested in the development of dietary products and strategies for treatment of obesity. Improved understanding of the mechanisms underpinning appetite response and eating behaviour is likely required in order to develop novel modified or 'functional' foods that can successfully target overconsumption and aid weight loss. Whilst optimising food products to target circulating concentrations of GI 'satiety' peptides with intent to suppress hunger and desire to eat and promote fullness appears to be a reasonable strategy, our review of dietary studies shows that this may be a difficult target to achieve. These peptides are rapidly secreted postprandially, with numerous physiological roles including that of nutrient digestion and absorption, but whether they are causal in suppression of appetite and eating behaviour at the low circulating levels attained following a meal is far less clear.

Author Contributions: Study concept and design: S.D.P. and J.J.L.; Methodology: J.J.L.; Formal analysis: J.J.L.; Verification: S.D.P.; Manuscript draft: S.D.P. and J.J.L.

Funding: This research was supported by the Riddet Institute, a New Zealand Centre of Research Excellence (CoRE), funded by Tertiary Education Commission (TEC), including PhD scholarship funding for J.J.L.

Conflicts of Interest: S.D.P held the Fonterra Chair in Human Nutrition at the University of Auckland, Auckland, New Zealand; and funding from the NZ National Science Challenge High Value Nutrition programme. The authors declare no other conflicts of interest.

\section{References}

1. Chambers, L.; McCrickerd, K.; Yeomans, M.R. Optimising foods for satiety. Trends Food Sci. Technol. 2015, 41, 149-160. [CrossRef]

2. Poppitt, S.D.; Shin, H.S.; McGill, A.T.; Budgett, S.C.; Lo, K.; Pahl, M.; Duxfield, J.; Lane, M.; Ingram, J.R. Duodenal and ileal glucose infusions differentially alter gastrointestinal peptides, appetite response, and food intake: A tube feeding study. Am. J. Clin. Nutr. 2017, 106, 725-735. [CrossRef] [PubMed]

3. van Avesaat, M.; Ripken, D.; Hendriks, H.F.; Masclee, A.A.; Troost, F.J. Small intestinal protein infusion in humans: Evidence for a location-specific gradient in intestinal feedback on food intake and GI peptide release. Int. J. Obes. 2017, 41, 217-224. [CrossRef] [PubMed]

4. Lacy, B.E.; Carter, J.; Weiss, J.E.; Crowell, M.D. The effects of intraduodenal nutrient infusion on serum CCK, LES pressure, and gastroesophageal reflux. Neurogastroenterol. Motil. 2011, 23, 631-e256. [CrossRef] [PubMed]

5. Giezenaar, C.; Luscombe-Marsh, N.D.; Hutchison, A.T.; Standfield, S.; Feinle-Bisset, C.; Horowitz, M.; Chapman, I.; Soenen, S. Dose-dependent effects of randomized intraduodenal whey-protein loads on glucose, gut hormone, and amino acid concentrations in healthy older and younger men. Nutrients 2018, 10. [CrossRef] [PubMed]

6. Ryan, A.T.; Luscombe-Marsh, N.D.; Saies, A.A.; Little, T.J.; Standfield, S.; Horowitz, M.; Feinle-Bisset, C. Effects of intraduodenal lipid and protein on gut motility and hormone release, glycemia, appetite, and energy intake in lean men. Am. J. Clin. Nutr. 2013, 98, 300-311. [CrossRef] [PubMed]

7. Maljaars, P.W.J.; van der Wal, R.J.P.; Wiersma, T.; Peters, H.P.F.; Haddeman, E.; Masclee, A.A.M. The effect of lipid droplet size on satiety and peptide secretion is intestinal site-specific. Clin. Nutr. 2012, 31, 535-542. [CrossRef] [PubMed]

8. Schmidt, W.E.; Creutzfeldt, W.; Schleser, A.; Choudhury, A.R.; Nustede, R.; Hocker, M.; Nitsche, R.; Sostmann, H.; Rovati, L.C.; Folsch, U.R. Role of CCK in regulation of pancreaticobiliary functions and GI motility in humans: Effects of loxiglumide. Am. J. Physiol. 1991, 260, G197-G206. [CrossRef]

9. Holst, J.J.; Gromada, J. Role of incretin hormones in the regulation of insulin secretion in diabetic and nondiabetic humans. Am. J. Physiol. Endocrinol. Metab. 2004, 287, E199-E206. [CrossRef]

10. Savage, A.P.; Adrian, T.E.; Carolan, G.; Chatterjee, V.K.; Bloom, S.R. Effects of Peptide YY (PYY) on mouth to caecum intestinal transit time and on the rate of gastric emptying in healthy volunteers. Gut 1987, 28, 166-170. [CrossRef] 
11. Blundell, J.; de Graaf, C.; Hulshof, T.; Jebb, S.; Livingstone, B.; Lluch, A.; Mela, D.; Salah, S.; Schuring, E.; van der Knaap, H.; et al. Appetite control: Methodological aspects of the evaluation of foods. Obes. Rev. 2010, 11, 251-270. [CrossRef] [PubMed]

12. Prinz, P.; Stengel, A. Control of food intake by gastrointestinal peptides: Mechanisms of action and possible modulation in the treatment of obesity. J. Neurogastroenterol. Motil. 2017, 23, 180-196. [CrossRef] [PubMed]

13. Drucker, D.J. Mechanisms of action and therapeutic application of glucagon-like peptide-1. Cell Metab. 2018, 27, 740-756. [CrossRef] [PubMed]

14. Neary, M.T.; Batterham, R.L. Gut hormones: Implications for the treatment of obesity. Pharmacl. Ther. 2009, 124, 44-56. [CrossRef] [PubMed]

15. Htike, Z.Z.; Zaccardi, F.; Papamargaritis, D.; Webb, D.R.; Khunti, K.; Davies, M.J. Efficacy and safety of glucagon-like peptide-1 receptor agonists in type 2 diabetes: A systematic review and mixed-treatment comparison analysis. Diabetes Obes. Metab. 2017, 19, 524-536. [CrossRef] [PubMed]

16. de Boer, S.A.; Lefrandt, J.D.; Petersen, J.F.; Boersma, H.H.; Mulder, D.J.; Hoogenberg, K. The effects of GLP-1 analogues in obese, insulin-using type 2 diabetes in relation to eating behaviour. Int. J. Clin. Pharm. 2016, 38, 144-151. [CrossRef] [PubMed]

17. Vilsbøll, T.; Christensen, M.; Junker, A.E.; Knop, F.K.; Gluud, L.L. Effects of glucagon-like peptide-1 receptor agonists on weight loss: Systematic review and meta-analyses of randomised controlled trials. BMJ 2012, 344, D7771. [CrossRef]

18. Mars, M.; Stafleu, A.; de Graaf, C. Use of satiety peptides in assessing the satiating capacity of foods. Physiol. Behav. 2012, 105, 483-488. [CrossRef]

19. Veldhorst, M.A.; Nieuwenhuizen, A.G.; Hochstenbach-Waelen, A.; van Vught, A.J.; Westerterp, K.R.; Engelen, M.P.; Brummer, R.J.; Deutz, N.E.; Westerterp-Plantenga, M.S. Dose-dependent satiating effect of whey relative to casein or soy. Physiol. Behav. 2009, 96, 675-682. [CrossRef]

20. Dougkas, A.; Ostman, E. Protein-enriched liquid preloads varying in macronutrient content modulate appetite and appetite-regulating hormones in healthy adults. J. Nutr. 2016, 146, 637-645. [CrossRef]

21. Smeets, A.J.; Westerterp-Plantenga, M.S. The acute effects of a lunch containing capsaicin on energy and substrate utilisation, hormones, and satiety. Eur. J. Nutr. 2009, 48, 229-234. [CrossRef] [PubMed]

22. Smeets, A.J.; Soenen, S.; Luscombe-Marsh, N.D.; Ueland, O.; Westerterp-Plantenga, M.S. Energy expenditure, satiety, and plasma ghrelin, glucagon-like peptide 1 , and peptide tyrosine-tyrosine concentrations following a single high-protein lunch. J. Nutr. 2008, 138, 698-702. [CrossRef] [PubMed]

23. Nolan, L.J.; Guss, J.L.; Liddle, R.A.; Pi-Sunyer, F.X.; Kissileff, H.R. Elevated plasma cholecystokinin and appetitive ratings after consumption of a liquid meal in humans. Nutrition 2003, 19, 553-557. [CrossRef]

24. Hall, W.L.; Millward, D.J.; Long, S.J.; Morgan, L.M. Casein and whey exert different effects on plasma amino acid profiles, gastrointestinal hormone secretion and appetite. Br. J. Nutr. 2003, 89, 239-248. [CrossRef] [PubMed]

25. Bakhoj, S.; Flint, A.; Holst, J.J.; Tetens, I. Lower glucose-dependent insulinotropic polypeptide (GIP) response but similar glucagon-like peptide 1 (GLP-1), glycaemic, and insulinaemic response to ancient wheat compared to modern wheat depends on processing. Eur. J. Clin. Nutr. 2003, 57, 1254-1261. [CrossRef] [PubMed]

26. Frost, G.S.; Brynes, A.E.; Dhillo, W.S.; Bloom, S.R.; McBurney, M.I. The effects of fiber enrichment of pasta and fat content on gastric emptying, GLP-1, glucose, and insulin responses to a meal. Eur. J. Clin. Nutr. 2003, 57, 293-298. [CrossRef] [PubMed]

27. Pasman, W.J.; Blokdijk, V.M.; Bertina, F.M.; Hopman, W.P.; Hendriks, H.F. Effect of two breakfasts, different in carbohydrate composition, on hunger and satiety and mood in healthy men. Int. J. Obes. Relat. Metab. Disord. 2003, 27, 663-668. [CrossRef] [PubMed]

28. Adam, T.C.M. Glucagon-Like Peptide 1 Stimulation in Relation to Body Weight; University Maastricht: Maastricht, The Netherlands, 2004.

29. Sanggaard, K.M.; Holst, J.J.; Rehfeld, J.F.; Sandstrom, B.; Raben, A.; Tholstrup, T. Different effects of whole milk and a fermented milk with the same fat and lactose content on gastric emptying and postprandial lipaemia, but not on glycaemic response and appetite. Br. J. Nutr. 2004, 92, 447-459. [CrossRef]

30. Burton-Freeman, B. Sex and cognitive dietary restraint influence cholecystokinin release and satiety in response to preloads varying in fatty acid composition and content. J. Nutr. 2005, 135, 1407-1414. [CrossRef]

31. Adam, T.C.; Westerterp-Plantenga, M.S. Glucagon-like peptide-1 release and satiety after a nutrient challenge in normal-weight and obese subjects. Br. J. Nutr. 2005, 93, 845-851. [CrossRef] 
32. Weickert, M.O.; Mohlig, M.; Koebnick, C.; Holst, J.J.; Namsolleck, P.; Ristow, M.; Osterhoff, M.; Rochlitz, H.; Rudovich, N.; Spranger, J.; et al. Impact of cereal fibre on glucose-regulating factors. Diabetologia 2005, 48, 2343-2353. [CrossRef] [PubMed]

33. Batterham, R.L.; Heffron, H.; Kapoor, S.; Chivers, J.E.; Chandarana, K.; Herzog, H.; Le Roux, C.W.; Thomas, E.L.; Bell, J.D.; Withers, D.J. Critical role for Peptide YY in protein-mediated satiation and body-weight regulation. Cell Metab. 2006, 4, 223-233. [CrossRef] [PubMed]

34. Blom, W.A.; Lluch, A.; Stafleu, A.; Vinoy, S.; Holst, J.J.; Schaafsma, G.; Hendriks, H.F. Effect of a high-protein breakfast on the postprandial ghrelin response. Am. J. Clin. Nutr. 2006, 83, 211-220. [CrossRef] [PubMed]

35. le Roux, C.W.; Batterham, R.L.; Aylwin, S.J.; Patterson, M.; Borg, C.M.; Wynne, K.J.; Kent, A.; Vincent, R.P.; Gardiner, J.; Ghatei, M.A.; et al. Attenuated Peptide YY release in obese subjects is associated with reduced satiety. Endocrinology 2006, 147, 3-8. [CrossRef] [PubMed]

36. Weickert, M.O.; Spranger, J.; Holst, J.J.; Otto, B.; Koebnick, C.; Mohlig, M.; Pfeiffer, A.F. Wheat-fibre-induced changes of postprandial Peptide YY and ghrelin responses are not associated with acute alterations of satiety. Br. J. Nutr. 2006, 96, 795-798. [CrossRef] [PubMed]

37. Doucet, E.; Laviolette, M.; Imbeault, P.; Strychar, I.; Rabasa-Lhoret, R.; Prud'homme, D. Total Peptide YY is a correlate of postprandial energy expenditure but not of appetite or energy intake in healthy women. Metabolism 2008, 57, 1458-1464. [CrossRef] [PubMed]

38. Sorensen, L.B.; Cueto, H.T.; Andersen, M.T.; Bitz, C.; Holst, J.J.; Rehfeld, J.F.; Astrup, A. The effect of salatrim, a low-calorie modified triacylglycerol, on appetite and energy intake. Am. J. Clin. Nutr. 2008, 87, 1163-1169. [CrossRef]

39. Zijlstra, N.; Mars, M.; de Wijk, R.A.; Westerterp-Plantenga, M.S.; Holst, J.J.; de Graaf, C. Effect of viscosity on appetite and gastro-intestinal hormones. Physiol. Behav. 2009, 97, 68-75. [CrossRef]

40. Hlebowicz, J.; Hlebowicz, A.; Lindstedt, S.; Bjorgell, O.; Hoglund, P.; Holst, J.J.; Darwiche, G.; Almer, L.O. Effects of 1 and $3 \mathrm{~g}$ cinnamon on gastric emptying, satiety, and postprandial blood glucose, insulin, glucose-dependent insulinotropic polypeptide, glucagon-like peptide 1, and ghrelin concentrations in healthy subjects. Am. J. Clin. Nutr. 2009, 89, 815-821. [CrossRef]

41. Veldhorst, M.A.; Nieuwenhuizen, A.G.; Hochstenbach-Waelen, A.; Westerterp, K.R.; Engelen, M.P.; Brummer, R.J.; Deutz, N.E.; Westerterp-Plantenga, M.S. Effects of complete whey-protein breakfasts versus whey without GMP-breakfasts on energy intake and satiety. Appetite 2009, 52, 388-395. [CrossRef]

42. Veldhorst, M.A.; Nieuwenhuizen, A.G.; Hochstenbach-Waelen, A.; Westerterp, K.R.; Engelen, M.P.; Brummer, R.J.; Deutz, N.E.; Westerterp-Plantenga, M.S. Comparison of the effects of a high- and normal-casein breakfast on satiety, 'satiety' hormones, plasma amino acids and subsequent energy intake. Br. J. Nutr. 2009, 101, 295-303. [CrossRef] [PubMed]

43. Veldhorst, M.A.; Nieuwenhuizen, A.G.; Hochstenbach-Waelen, A.; Westerterp, K.R.; Engelen, M.P.; Brummer, R.J.; Deutz, N.E.; Westerterp-Plantenga, M.S. Effects of high and normal soyprotein breakfasts on satiety and subsequent energy intake, including amino acid and 'satiety' hormone responses. Eur. J. Nutr. 2009, 48, 92-100. [CrossRef] [PubMed]

44. Nieuwenhuizen, A.G.; Hochstenbach-Waelen, A.; Veldhorst, M.A.; Westerterp, K.R.; Engelen, M.P.; Brummer, R.J.; Deutz, N.E.; Westerterp-Plantenga, M.S. Acute effects of breakfasts containing alpha-lactalbumin, or gelatin with or without added tryptophan, on hunger, 'satiety' hormones and amino acid profiles. Br. J. Nutr. 2009, 101, 1859-1866. [CrossRef] [PubMed]

45. Kohnke, R.; Lindbo, A.; Larsson, T.; Lindqvist, A.; Rayner, M.; Emek, S.C.; Albertsson, P.A.; Rehfeld, J.F.; Landin-Olsson, M.; Erlanson-Albertsson, C. Thylakoids promote release of the satiety hormone cholecystokinin while reducing insulin in healthy humans. Scand. J. Gastroenterol. 2009, 44, 712-719. [CrossRef] [PubMed]

46. Juvonen, K.R.; Salmenkallio-Marttila, M.; Lyly, M.; Liukkonen, K.H.; Lahteenmaki, L.; Laaksonen, D.E.; Uusitupa, M.I.; Herzig, K.H.; Poutanen, K.S.; Karhunen, L.J. Semisolid meal enriched in oat bran decreases plasma glucose and insulin levels, but does not change gastrointestinal peptide responses or short-term appetite in healthy subjects. Nutr. Metab. Cardiovasc. Dis. 2011, 21, 748-756. [CrossRef] [PubMed]

47. Juvonen, K.R.; Karhunen, L.J.; Vuori, E.; Lille, M.E.; Karhu, T.; Jurado-Acosta, A.; Laaksonen, D.E.; Mykkanen, H.M.; Niskanen, L.K.; Poutanen, K.S.; et al. Structure modification of a milk protein-based model food affects postprandial intestinal peptide release and fullness in healthy young men. Br. J. Nutr. 2011, 106, 1890-1898. [CrossRef] [PubMed] 
48. Brennan, I.M.; Luscombe-Marsh, N.D.; Seimon, R.V.; Otto, B.; Horowitz, M.; Wishart, J.M.; Feinle-Bisset, C. Effects of fat, protein, and carbohydrate and protein load on appetite, plasma cholecystokinin, Peptide YY, and ghrelin, and energy intake in lean and obese men. Am. J. Physiol. Gastrointest. Liver Physiol. 2012, 303, G129-G140. [CrossRef] [PubMed]

49. Kim, S.J.; Lee, H.; Choue, R. Short-term effects of ratio of energy nutrients on appetite-related hormones in female college students. Clin. Nutr. Res. 2012, 1, 58-65. [CrossRef] [PubMed]

50. Zhu, Y.; Hsu, W.H.; Hollis, J.H. The effect of food form on satiety. Int. J. Food Sci. Nutr. 2013, 64, 385-391. [CrossRef] [PubMed]

51. van der Klaauw, A.A.; Keogh, J.M.; Henning, E.; Trowse, V.M.; Dhillo, W.S.; Ghatei, M.A.; Farooqi, I.S. High protein intake stimulates postprandial GLP1 and PYY release. Obesity 2013, 21, 1602-1607. [CrossRef]

52. Little, T.J.; Luscombe-Marsh, N.D.; Gentilcore, D.; Brook, E.J.; Feinle-Bisset, C. Effects of varying the inter-meal interval on relationships between antral area, gut hormones and energy intake following a nutrient drink in healthy lean humans. Physiol. Behav. 2014, 135, 34-43. [CrossRef] [PubMed]

53. Zhu, Y.; Hollis, J.H. Gastric emptying rate, glycemic and appetite response to a liquid meal in lean and overweight males. Int. J. Food Sci. Nutr. 2014, 65, 615-620. [CrossRef] [PubMed]

54. Ohlsson, L.; Rosenquist, A.; Rehfeld, J.F.; Harrod, M. Postprandial effects on plasma lipids and satiety hormones from intake of liposomes made from fractionated oat oil: Two randomized crossover studies. Food Nutr. Res. 2014, 58. [CrossRef] [PubMed]

55. Chungchunlam, S.M.; Henare, S.J.; Ganesh, S.; Moughan, P.J. Dietary whey protein influences plasma satiety-related hormones and plasma amino acids in normal-weight adult women. Eur. J. Clin. Nutr. 2015, 69, 179-186. [CrossRef] [PubMed]

56. Bligh, H.F.; Godsland, I.F.; Frost, G.; Hunter, K.J.; Murray, P.; MacAulay, K.; Hyliands, D.; Talbot, D.C.; Casey, J.; Mulder, T.P.; et al. Plant-rich mixed meals based on palaeolithic diet principles have a dramatic impact on incretin, Peptide YY and satiety response, but show little effect on glucose and insulin homeostasis: An acute-effects randomised study. Br. J. Nutr. 2015, 113, 574-584. [CrossRef] [PubMed]

57. Clamp, L.; Hehir, A.P.; Lambert, E.V.; Beglinger, C.; Goedecke, J.H. Lean and obese dietary phenotypes: Differences in energy and substrate metabolism and appetite. Br. J. Nutr. 2015, 114, 1724-1733. [CrossRef] [PubMed]

58. Hutchison, A.T.; Piscitelli, D.; Horowitz, M.; Jones, K.L.; Clifton, P.M.; Standfield, S.; Hausken, T.; Feinle-Bisset, C.; Luscombe-Marsh, N.D. Acute load-dependent effects of oral whey protein on gastric emptying, gut hormone release, glycemia, appetite, and energy intake in healthy men. Am. J. Clin. Nutr. 2015, 102, 1574-1584. [CrossRef] [PubMed]

59. Gonzalez-Anton, C.; Lopez-Millan, B.; Rico, M.C.; Sanchez-Rodriguez, E.; Ruiz-Lopez, M.D.; Gil, A.; Mesa, M.D. An enriched, cereal-based bread affects appetite ratings and glycemic, insulinemic, and gastrointestinal hormone responses in healthy adults in a randomized, controlled trial. J. Nutr. 2015, 145, 231-238. [CrossRef] [PubMed]

60. Overduin, J.; Collet, T.H.; Medic, N.; Henning, E.; Keogh, J.M.; Forsyth, F.; Stephenson, C.; Kanning, M.W.; Ruijschop, R.; Farooqi, I.S.; et al. Failure of sucrose replacement with the non-nutritive sweetener erythritol to alter GLP-1 or PYY release or test meal size in lean or obese people. Appetite 2016, 107, 596-603. [CrossRef] [PubMed]

61. Lieverse, R.J.; Jansen, J.B.; Masclee, A.A.; Lamers, C.B. Satiety effects of a physiological dose of cholecystokinin in humans. Gut 1995, 36, 176-179. [CrossRef] [PubMed]

62. Ballinger, A.; McLoughlin, L.; Medbak, S.; Clark, M. Cholecystokinin is a satiety hormone in humans at physiological post-prandial plasma concentrations. Clin. Sci. 1995, 89, 375-381. [CrossRef] [PubMed]

63. Lieverse, R.J.; Jansen, J.B.M.J.; van de Zwan, A.; Samson, L.; Masclee, A.A.M.; Lamers, C.B.H.W. Effects of a physiological dose of cholecystokinin on food intake and postprandial satiation in man. Regul. Pept. 1993, 43, 83-89. [CrossRef]

64. Gutzwiller, J.-P.; Drewe, J.; Ketterer, S.; Hildebrand, P.; Krautheim, A.; Beglinger, C. Interaction between CCK and a preload on reduction of food intake is mediated by CCK-A receptors in humans. Am. J. Physiol. Regul. Integr. Comp. Physiol. 2000, 279, R189-R195. [CrossRef] [PubMed] 
65. MacIntosh, C.G.; Morley, J.E.; Wishart, J.; Morris, H.; Jansen, J.B.; Horowitz, M.; Chapman, I.M. Effect of exogenous cholecystokinin (CCK)-8 on food intake and plasma CCK, leptin, and insulin concentrations in older and young adults: Evidence for increased cck activity as a cause of the anorexia of aging. J. Clin. Endocrinol. Metab. 2001, 86, 5830-5837. [CrossRef] [PubMed]

66. Gutzwiller, J.-P.; Degen, L.; Matzinger, D.; Prestin, S.; Beglinger, C. Interaction between GLP-1 and CCK-33 in inhibiting food intake and appetite in men. Am. J. Physiol. Regul. Integr. Comp. Physiol. 2004, 287, R562-R567. [CrossRef] [PubMed]

67. Brennan, I.M.; Feltrin, K.L.; Horowitz, M.; Smout, A.J.; Meyer, J.H.; Wishart, J.; Feinle-Bisset, C. Evaluation of interactions between CCK and GLP-1 in their effects on appetite, energy intake, and antropyloroduodenal motility in healthy men. Am. J. Physiol. Regul. Integr. Comp Physiol. 2005, 288, R1477-R1485. [CrossRef] [PubMed]

68. Flint, A.; Raben, A.; Astrup, A.; Holst, J.J. Glucagon-like peptide 1 promotes satiety and suppresses energy intake in humans. J. Clin. Investig. 1998, 101, 515-520. [CrossRef] [PubMed]

69. Gutzwiller, J.P.; Goke, B.; Drewe, J.; Hildebrand, P.; Ketterer, S.; Handschin, D.; Winterhalder, R.; Conen, D.; Beglinger, C. Glucagon-like peptide-1: A potent regulator of food intake in humans. Gut 1999, 44, 81-86. [CrossRef] [PubMed]

70. Long, S.J.; Sutton, J.A.; Amaee, W.B.; Giouvanoudi, A.; Spyrou, N.M.; Rogers, P.J.; Morgan, L.M. No effect of glucagon-like peptide-1 on short-term satiety and energy intake in man. Br. J. Nutr 1999, 81, 273-279. [CrossRef] [PubMed]

71. Nagell, C.F.; Wettergren, A.; Pedersen, J.F.; Mortensen, D.; Holst, J.J. Glucagon-like peptide-2 inhibits antral emptying in man, but is not as potent as glucagon-like peptide-1. Scand. J. Gastroenterol. 2004, 39, 353-358. [CrossRef] [PubMed]

72. Neary, N.M.; Small, C.J.; Druce, M.R.; Park, A.J.; Ellis, S.M.; Semjonous, N.M.; Dakin, C.L.; Filipsson, K.; Wang, F.; Kent, A.S.; et al. Peptide YY3-36 and glucagon-like peptide-17-36 inhibit food intake additively. Endocrinology 2005, 146, 5120-5127. [CrossRef] [PubMed]

73. Little, T.J.; Pilichiewicz, A.N.; Russo, A.; Phillips, L.; Jones, K.L.; Nauck, M.A.; Wishart, J.; Horowitz, M.; Feinle-Bisset, C. Effects of intravenous glucagon-like peptide-1 on gastric emptying and intragastric distribution in healthy subjects: Relationships with postprandial glycemic and insulinemic responses. J. Clin. Endocrinol. Metab. 2006, 91, 1916-1923. [CrossRef] [PubMed]

74. Batterham, R.L.; Cowley, M.A.; Small, C.J.; Herzog, H.; Cohen, M.A.; Dakin, C.L.; Wren, A.M.; Brynes, A.E.; Low, M.J.; Ghatei, M.A.; et al. Gut hormone PYY3-36 physiologically inhibits food intake. Nature 2002, 418, 650-654. [CrossRef] [PubMed]

75. Degen, L.; Oesch, S.; Casanova, M.; Graf, S.; Ketterer, S.; Drewe, J.; Beglinger, C. Effect of Peptide YY3-36 on food intake in humans. Gastroenterology 2005, 129, 1430-1436. [CrossRef] [PubMed]

76. Batterham, R.L.; ffytche, D.H.; Rosenthal, J.M.; Zelaya, F.O.; Barker, G.J.; Withers, D.J.; Williams, S.C. PYY modulation of cortical and hypothalamic brain areas predicts feeding behaviour in humans. Nature 2007, 450, 106-109. [CrossRef] [PubMed]

77. le Roux, C.W.; Borg, C.M.; Murphy, K.G.; Vincent, R.P.; Ghatei, M.A.; Bloom, S.R. Supraphysiological doses of intravenous PYY3-36 cause nausea, but no additional reduction in food intake. Ann. Clin. Biochem. 2008, 45, 93-95. [CrossRef] [PubMed]

78. Deacon, C.F.; Pridal, L.; Klarskov, L.; Olesen, M.; Holst, J.J. Glucagon-like peptide 1 undergoes differential tissue-specific metabolism in the anesthetized pig. Am. J. Physiol. 1996, 271, E458-E464. [CrossRef] [PubMed]

79. Hansen, L.; Deacon, C.F.; Ørskov, C.; Holst, J.J. Glucagon-like peptide-1-(7-36)amide is transformed to glucagon-like peptide-1-(9-36)amide by dipeptidyl peptidase IV in the capillaries supplying the L cells of the porcine intestine. Endocrinology 1999, 140, 5356-5363. [CrossRef] [PubMed]

80. Brennan, I.M.; Little, T.J.; Feltrin, K.L.; Smout, A.J.; Wishart, J.M.; Horowitz, M.; Feinle-Bisset, C. Dose-dependent effects of cholecystokinin-8 on antropyloroduodenal motility, gastrointestinal hormones, appetite, and energy intake in healthy men. Am. J. Physiol. Endocrinol. Metab 2008, 295, E1487-E1494. [CrossRef] [PubMed]

81. Dockray, G.J. Cholecystokinin and gut-brain signalling. Regul. Pept. 2009, 155, 6-10. [CrossRef]

82. Steinert, R.E.; Feinle-Bisset, C.; Asarian, L.; Horowitz, M.; Beglinger, C.; Geary, N. Ghrelin, CCK, GLP-1, and PYY(3-36): Secretory controls and physiological roles in eating and glycemia in health, obesity, and after RYGB. Physiol. Rev. 2017, 97, 411-463. [CrossRef] [PubMed] 
83. Greenberg, D.; Smith, G.P. Hepatic-portal infusion reduces the satiating potency of CCK-8. Physiol. Behav. 1988, 44, 535-538. [CrossRef]

84. Dailey, M.J.; Moran, T.H. Glucagon-like peptide 1 and appetite. Trends Endocrinol. Metab. 2013, $24,85-91$. [CrossRef] [PubMed]

85. Poppitt, S.D.; McCormack, D.; Buffenstein, R. Short-term effects of macronutrient preloads on appetite and energy intake in lean women. Physiol. Behav. 1998, 64, 279-285. [CrossRef]

86. Juvonen, K.R.; Purhonen, A.K.; Salmenkallio-Marttila, M.; Lahteenmaki, L.; Laaksonen, D.E.; Herzig, K.H.; Uusitupa, M.I.; Poutanen, K.S.; Karhunen, L.J. Viscosity of oat bran-enriched beverages influences gastrointestinal hormonal responses in healthy humans. J. Nutr. 2009, 139, 461-466. [CrossRef] [PubMed]

87. Karhunen, L.J.; Juvonen, K.R.; Flander, S.M.; Liukkonen, K.H.; Lahteenmaki, L.; Siloaho, M.; Laaksonen, D.E.; Herzig, K.H.; Uusitupa, M.I.; Poutanen, K.S. A psyllium fiber-enriched meal strongly attenuates postprandial gastrointestinal peptide release in healthy young adults. J. Nutr. 2010, 140, 737-744. [CrossRef] [PubMed]

88. Vitaglione, P.; Lumaga, R.B.; Stanzione, A.; Scalfi, L.; Fogliano, V. Beta-glucan-enriched bread reduces energy intake and modifies plasma ghrelin and Peptide YY concentrations in the short term. Appetite 2009, 53, 338-344. [CrossRef]

89. Poutanen, K.S.; Dussort, P.; Erkner, A.; Fiszman, S.; Karnik, K.; Kristensen, M.; Marsaux, C.F.; Miquel-Kergoat, S.; Pentikainen, S.P.; Putz, P.; et al. A review of the characteristics of dietary fibers relevant to appetite and energy intake outcomes in human intervention trials. Am. J. Clin. Nutr. 2017, 106, 747-754. [CrossRef]

90. Wanders, A.J.; van den Borne, J.J.G.C.; de Graaf, C.; Hulshof, T.; Jonathan, M.C.; Kristensen, M.; Mars, M.; Schols, H.A.; Feskens, E.J.M. Effects of dietary fibre on subjective appetite, energy intake and body weight: A systematic review of randomized controlled trials. Obes. Rev. 2011, 12, 724-739. [CrossRef]

91. Hill, B.R.; De Souza, M.J.; Wagstaff, D.A.; Sato, R.; Williams, N.I. 24-hour profiles of circulating ghrelin and Peptide YY are inversely associated in normal weight premenopausal women. Peptides 2012, 38, 159-162. [CrossRef]

92. MacLean, P.S.; Blundell, J.E.; Mennella, J.A.; Batterham, R.L. Biological control of appetite: A daunting complexity. Obesity 2017, 25, S8-S16. [CrossRef] [PubMed]

93. Giezenaar, C.; Luscombe-Marsh, N.D.; Hutchison, A.T.; Lange, K.; Hausken, T.; Jones, K.L.; Horowitz, M.; Chapman, I.; Soenen, S. Effect of gender on the acute effects of whey protein ingestion on energy intake, appetite, gastric emptying and gut hormone responses in healthy young adults. Nutr. Diabetes 2018, 8, 40. [CrossRef] [PubMed]

94. Drapeau, V.; Blundell, J.; Gallant, A.R.; Arguin, H.; Despres, J.P.; Lamarche, B.; Tremblay, A. Behavioural and metabolic characterisation of the low satiety phenotype. Appetite 2013, 70, 67-72. [CrossRef] [PubMed] 